\title{
Kaotik Haritalı Çok Amaçı Altın Sinüs Algoritmasının Performans Analizi
}

\author{
Eyüp ERÖZ ${ }^{*}$, Erkan TANYILDIZI ${ }^{2}$ \\ ${ }^{1}$ Yazılım Mühendisliği, Teknoloji Fakültesi, Fırat Üniversitesi, Elazı̆̆, Türkiye \\ ${ }^{2}$ Yazılım Mühendisliği, Teknoloji Fakültesi, Fırat Üniversitesi, Elazı̆̆ Türkiye \\ *1 erozeyup@gmail.com, ${ }^{2}$ etanyildizi@gmail.com
}

Öz: Çok amaçlı optimizasyon birden fazla amacı olan kısıtlı veya kısıtsız problemlere uygun çözümler üretme işlemidir. Sezgisel çok amaçlı optimizasyonda global optimuma yakın çözümler elde etmede rastgele üretilen sayı dizesi büyük öneme sahiptir. Rasgele üretilen sayı dizesinin belli bir alanda toplanması, global optimumdan uzaklaşma riskini arttırmaktadır. Bu nedenle üretilen sayıların aynı olmaması ve yayılmış bir spektruma sahip olması sezgisel optimizasyon algoritmalarının performansını etkilemektedir. Kaotik haritalar ayrık zamanlı sistemlerdir ve kaotik haritalarla üretilen sayılar geniş bir spektruma sahip olup periyodik değildir. Kaos temelli optimizasyon algoritmaları doğası gereği lokal minimumlardan kaçabilme, hızlı ve esnek olabilme gibi faktörlerden dolayı optimizasyon problemlerinin çözümünde incelemeye değer bir konu haline gelmiştir. Bu nedenle sezgisel çok amaçlı optimizasyon algoritmalarında, kaotik harita kullanılarak lokal optimuma takılma riskinin azaltılması hedeflenmiştir. Bu çalışmada kaotik haritaların, yeni ve başarılı olan Çok Amaçlı Altın Sinüs Algoritması (MOGoldSA) üzerindeki etkileri incelenmiştir.

Anahtar kelimeler: Kaotik harita, Çok Amaçlı optimizasyon, sezgisel yöntemler.

\section{Performance Analysis of Multiobjective Golden Sine Algorithm with Chaotic Map}

\begin{abstract}
Multiobjective optimization is the process of producing solutions suitable for limited or unconstrained problems with more than one purpose. In intuitive multi-objective optimization, the randomly generated number string is of great importance in obtaining solutions close to the global optimum. Collecting the randomly generated number string in a certain area increases the risk of diverging from the global optimum. Therefore, the numbers produced are not the same and have a spread spectrum affects the performance of heuristic optimization algorithms. Chaotic maps are discrete time systems and the numbers produced with chaotic maps have a wide spectrum and are not periodic. Due to the nature of chaos-based optimization algorithms, it has become a subject to be examined in the solution of optimization problems due to factors such as being able to escape local minimums and being fast and flexible. Therefore, in intuitive multi-purpose optimization algorithms, it is aimed to reduce the risk of getting stuck in the local optimum by using chaotic map. In this study, the effects of chaotic maps on the new and successful Multiobjective Golden Sine Algorithm (MOGoldSA) were investigated.
\end{abstract}

Key words: Chaotic map, Multiobjective optimization, heuristic methods.

\section{Giriş}

Metasezgisel optimizasyon algoritmaları dönüşümü kolay, türevi olmayan, problemleri çözüm kapasitesi yüksek ve geniş bir kullanıma sahip olduğu için oldukça popüler bir alandır. Metasezgisel optimizasyon algoritmaları olayları fiziksel veya biyolojik olarak taklit ederek problemleri çözüme kavuştururlar [1]. Metasezgisel optimizasyon, rasgele üretilen bir sayı dizesinden yola çıkarak optimizasyon problemlerine uygun çözümler üretme işlemidir. Sezgisel optimizasyonda, problemler uygun çözümler üretirken başlangıç değerlerinin yani rasgele üretilen sayı dizelerinin önemi büyüktür. Rasgele sayı dizelerinin geniş bir spektruma sahip olmaması veya hep aynı değerleri üretmesi optimizasyon algoritmasının performansını etkilemektedir [2]. Bilindiği üzere sezgisel optimizasyonda amaç global optimuma uygun çözümler üretmektir. Bu doğrultuda başlangıçtaki rasgele sayı dizelerinin geniş bir spektrumda ve her defasında farklı değerler olarak üretilmesini sağlamak için kaotik haritalar kullanılmıştır [3].

Kaotik sistemler başlangıç koşullarına duyarlı dinamik sistemlerdir. Kaos teorisi ise kaotik dinamik sistemlerin çalışmasıdır. Kaos teorisinin en bilindik örneği olan "kelebek etkisi” de göz önüne alındığında temel mantık olarak başlangıç koşullarındaki küçük değişikliklerin sonuçlara etkisi büyük olmaktadır. Bu doğrultuda çok amaçlı optimizasyon algoritmalarının başlangıçtaki rasgele sayı dizesinin, kaotik haritalar ile belirlenmesinin optimizasyon problemlerine uygun çözümler üretmede daha hızlı ve etkili olacağı ön görülmüştür. Kaotik sayı

\footnotetext{
${ }^{*}$ Sorumlu yazar: erozeyup@gmail.com. Yazarların ORCID Numarası: ${ }^{1}$ 0000-0003-2670-0606, ${ }^{2}$ 0000-0003-2973-9389
} 
dizesinin üretilmesi ve saklanması oldukça kolaydır. Basit bir fonksiyon ile istenilen spektrumdaki sayıları üretmek kolaydır. Üretilen kaotik temelli sayı dizesi sayesinde optimizasyon algoritmaları lokal optimumdan kaçabilmektedir. $\mathrm{Bu}$ düşünce ile geliştirilen birçok kaotik temelli çok amaçlı optimizasyon algoritması bulunmaktadır. Bunlara örnek olarak; Kaotik temelli NSGA-II (CNSGAII) [4], Kaotik Çok Amaçlı Parçacık Sürü Optimizasyonu (CMOPSO) [5], Kaotik Çok Amaçlı Karga Arama Algoritması (CMOCSA) [6], Kaotik Çok Amaçlı Karınca Optimizasyon Algoritması (CMOAO) [7], Kaotik Çok Amaçlı Diferansiyel Evrim Algoritması (CMODE) [8], Kaotik Çok Amaçlı Yapay Arı Kolonisi Algoritması (CMOABC) [9] ve Çok Amaçlı Kaotik Evrim (MOCE) [10] verilebilir. Çok amaçlı altın sinüs algoritmasının kaotik olarak değerlendirilmesinin sebebi ise, kısıtll, kısıtsız ve mühendislik problemlerinde hızlı ve etkili sonuçlar üretmiş olmasıdır.

\section{2. Çok Amaçlı Altın Sinüs Algoritması (MOGoldSA)}

MOGoldSA, tek amaçlı optimizasyon algoritması olan Gold-SA' nın çok amaçlı problemler için uygulanabilir halidir. Gold-SA, sinüs fonksiyonundan yola çıkılarak geliştirilmiş matematik tabanlı metasezgisel bir tek amaçlı optimizasyon algoritmasıdır. Trigonometrik bir fonksiyon olan sinüs, "sin" kısaltması ile ifade edilmektedir. Sinüs, merkezi orijin olan 1 birimlik yarıçap dairesinde bir noktanın y eksenine göre koordinatıdır. Orijinden noktaya çizilen bir doğrunun y ekseniyle yaptığı açı kullanılarak ya da aynı açıya sahip bir dik üçgende, bu açının karşısındaki kenarın hipotenüse bölümüyle hesaplanmaktadır. Fonksiyonun tanım aralığı; [-1,1]. Sinüs fonksiyonu, değerleri düzenli aralıklarla tekrarlayan periyodik bir fonksiyondur. Sinüs fonksiyonunun süresi $2 \pi$ 'dir ve sinüs değerlerine sahip tüm birim daireler Şekil 1' de gösterildiği gibi taranabilir [11].

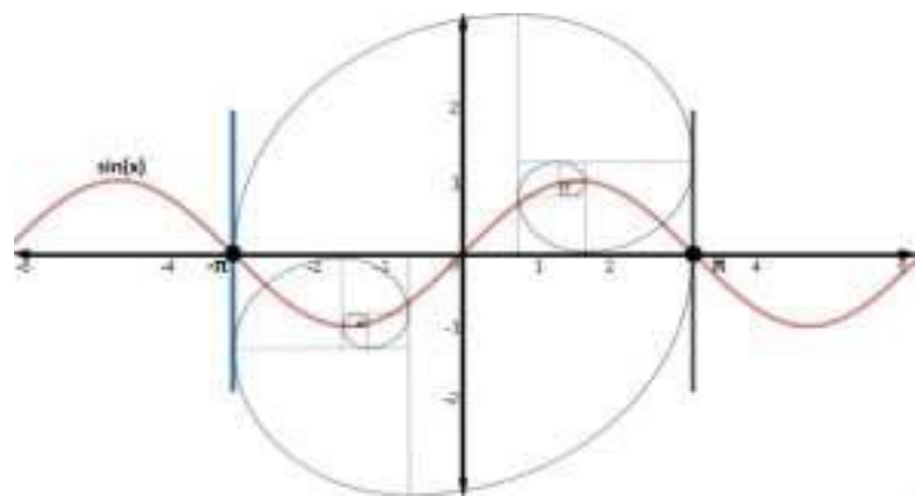

Şekil 1: GoldSA [11]

GoldSA' nın en iyi sonucu vermesi için denklem 1 kullanılır:

$$
V(i, j)=V(i, j) *\left|\sin r_{1}\right|-p * \sin r_{1} *\left|x_{1} * D(j)-x_{2} * V(i, j)\right|
$$

Burada, V (i,j), i. boyuttaki mevcut çözümün değeridir. $\mathrm{D}(\mathrm{j})$ belirlenen hedef değeri, $r_{1}[0,2 \pi]$ aralı̆ı̆ında ve $p[0, \pi]$ aralığında rastgele bir sayıdır. $x_{1}$ ve $x_{2}$ altın bölüm yöntemi ile elde edilen katsayılardır. Bu katsayılar arama alanını daraltır ve mevcut değerin hedef değere yaklaşmasına izin verir.

Gold-SA' nın problemlere çözümler üretirken, arama uzayını geniş şekilde taraması, optimuma yakın sonuç üretmesi ve hızlı çalışması gibi özelliklerinden hareketle çok amaçlı optimizasyon problemleri üzerinde de aynı başarıyı gösterebilir hipotezinden yola çıkarak MOGoldSA geliştirildi. MOGoldSA' nın arşiv boyutu dışındaki tüm parametreleri Gold-SA ile aynıdır. Bu doğrultuda MOGoldSA' nın sözde kodu şekil 2' de verilmiştir [12].

Çok Amaçlı Altın Sinüs Algoritması' nda $p$ parametresi her arama ajanı için $[0, \pi]$ aralığında rastgele olarak belirlenmektedir. Rasgele üretilen bu değerler arama uzayının geniş şekilde taranmasını engellemektedir. $\mathrm{Bu}$ sorunu ortadan kaldırmak için Mirjalili ve Amir H. Gandomi [13], kaotik haritaları Denklem 2 ve Denklem 3 ile normalize ederek başarııı sonuçlar elde etmişlerdir. Bu çalışmada normalize edilmiş kaotik haritalara entegre olarak adaptif olarak azalan Denklem 1'de gösterilen $r_{1}$ deseni ilk kez kullanılarak çok amaçlı optimizasyon problemlerine daha iyi çözümler bulabilmek için arama uzayının mümkün olduğunca tamamının taranması hedeflenmektedir. 


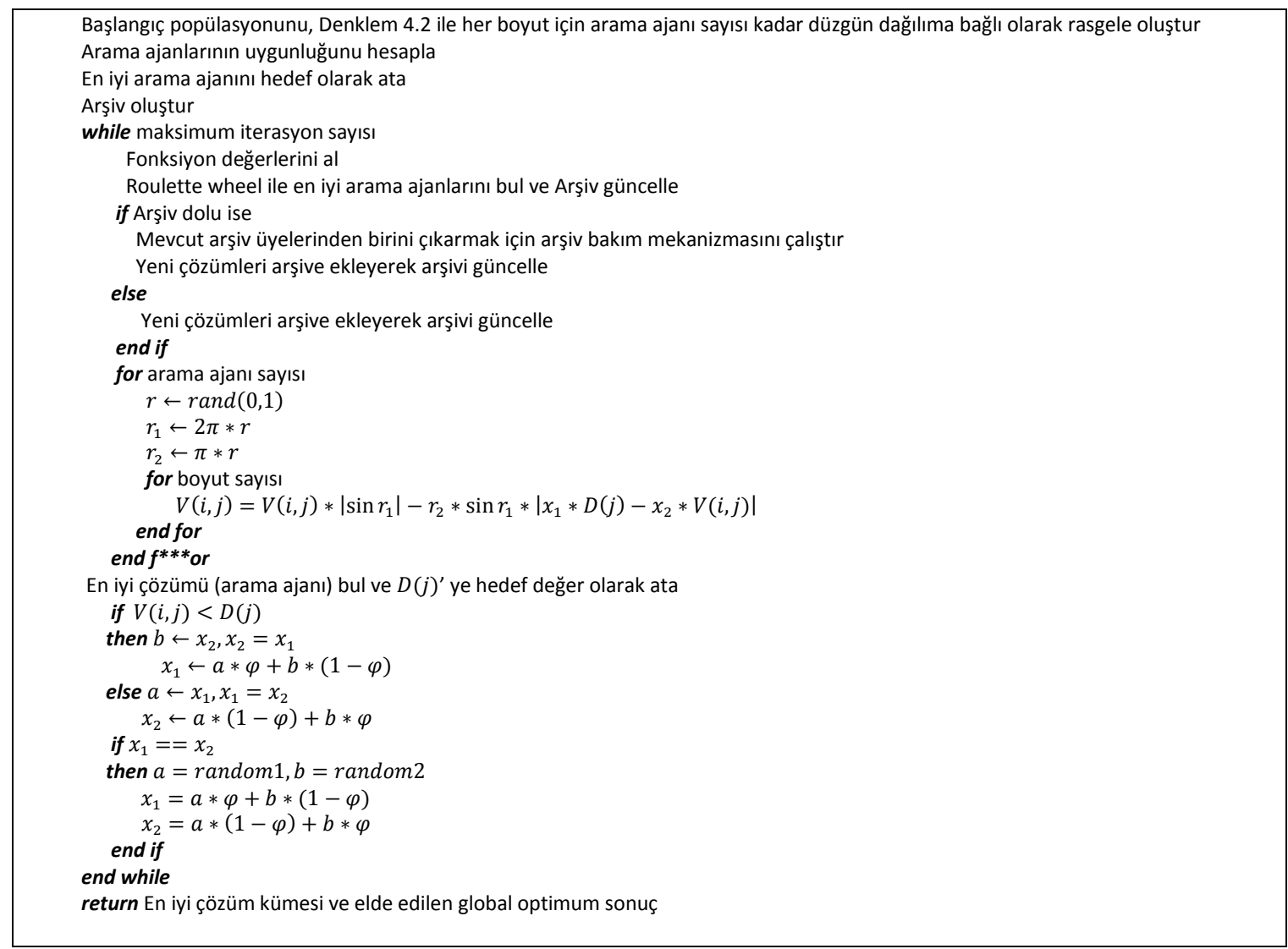

$$
\begin{aligned}
& \text { Şekil 2: MOGoldSA sözde kodu [12] } \\
& V(t)=\operatorname{Max}-\frac{t}{T}(\operatorname{Max}-\operatorname{Min}) \\
& \text { Normalize }\left(K_{i}(t) ;[a, b]^{\prime} \text { dan }[0, V(t)]^{\prime} y e\right): K_{i}^{\text {norm }}(t)=\frac{\left(K_{i}(t)-a\right) \times(V(t)-0)}{(b-a)}+0=\frac{\left(K_{i}(t)-a\right) \times(V(t))}{(b-a)}
\end{aligned}
$$

Burada, $K$ : Kaotik harita, $i$ : Kaotik haritanın indeksi, $t$ : Mevcut iterasyon, $T$ : Maksimum iterasyon sayıs1, $[$ Max - Min]: Uyarlanabilir aralığı temsil eder. $[a, b]$ : Kaotik haritaların aralığını gösterir. $V(t)$ her iterasyonda azaltılırken her iterasyonda $[a, b],[0, V(t)]$ ile eşleşir. Bu durum adaptif normalizasyon sürecini ifade eder. Sonuç olarak $p$ katsayısının değeri Denklem 4 kullanılarak güncelleştirilir.

$$
p(t)=K_{i}^{\text {norm }}(t)+c-t \times((c) / T)
$$

Rasgele üretilen diziye kaotik haritalar eklemek, hem adaptif $p$ 'nin hem de kaotik haritaların rasgele davranışlarına aynı anda katkıda bulunur. Kaotik haritalar her defasında farklı rasgele dizi üretilip geniş bir spektruma sahip olmayı sağlamaktadır. $p$ 'nin değerini aniden değiştirip yerel minimumdan kurtulmaya yardımcı olarak, daha iyi yakınsama hızı sağlamaktadır. Uyarlamalı normalleştirme ise kaos tabanlı MOGoldSA' nın arama evresinden sömürü evresine geçişini yavaşlatmayı sağlamaktadır.

\section{Kaotik Haritalı MOGoldSA Yöntemleri}

Literatürde birçok kaotik harita tanımlanmıştır. Bu çalışmada kullanılan kaotik haritalar Tablo 1' de verilmiştir. MOGoldSA' da rastgele değerler kullanan kısımlar kaotik harita denklemleri ile değiştirilerek MOGoldSA' nın on farklı kaotik versiyonu oluşturulmuştur. 
Tablo 1. Kaotik Haritalar [3]

\begin{tabular}{|c|c|c|c|}
\hline & Kaotik Harita & Foksiyon & \\
\hline $\mathrm{C} 1$ & Chebyshev & $x_{i+1}=\cos \left(i \cos ^{-1}\left(x_{i}\right)\right)$ & (5) \\
\hline $\mathrm{C} 2$ & Çember & $x_{i+1}=\bmod \left(x_{i}+b-\left(\frac{a}{2 \pi}\right) \sin \left(2 \pi x_{i}\right), 1\right), a=0.5, b=0.2$ & (6) \\
\hline $\mathrm{C} 3$ & Gauss/Mouse & $x_{i+1}=\left\{\begin{array}{cc}1 & x_{i}=0 \\
\frac{1}{\bmod \left(x_{i}, 1\right)} \text { aksi takdirde }\end{array}\right.$ & (7) \\
\hline C4 & İteratif & $x_{i+1}=\sin \left(\frac{a \pi}{x_{i}}\right) a=0.7$ & (8) \\
\hline C5 & Lojistik & $x_{i+1}=a x_{i}\left(1-x_{i}\right), a=4$ & (9) \\
\hline C6 & Parçalı & $x_{i+1}=\left\{\begin{array}{cc}\frac{x_{i}}{P} \\
\frac{x_{i}-P}{0.5-P} & 0 \leq x_{i}<P \\
\frac{1-P-x_{i}}{0.5-P} & P \leq x_{i}<0.5 \\
\frac{1-x_{i}}{P}\end{array} 0.5 \leq x_{i}<1-P, 1-P \leq x_{i}<1\right.$ & (10) \\
\hline $\mathrm{C} 7$ & Sinüs & $x_{i+1}=\frac{a}{4} \sin \left(\pi x_{i}\right) a=4$ & (11) \\
\hline $\mathrm{C} 8$ & Singer & $x_{i+1}=\mu\left(7.86 x_{i}-23.31 x_{i}^{2}+28.75 x_{i}^{3}-13.302875 x_{i}^{4}\right), \mu=2.3$ & (12) \\
\hline C9 & Sinüzoidal & $x_{i+1}=a x_{i}^{2} \sin \left(\pi x_{i}\right), a=2.3$ & (13) \\
\hline $\mathrm{C} 10$ & Tent & $x_{i+1}=\left\{\begin{array}{c}\frac{x_{i}}{0.7} x_{i}<0.7 \\
\frac{10}{3}\left(1-x_{i}\right) x_{i} \geq 0.7\end{array}\right.$ & (14) \\
\hline
\end{tabular}

\section{Deneysel Sonuçlar}

Geliştirilen yöntemin başarısını test etmek için literatürde yer alan 14 farklı kıyaslama fonksiyonu kullanılarak (kısıtll, kısıtsız ve mühendislik problemlerinin) performans değerleri incelenmiştir. Kullanılan mühendislik problemlerinin matematiksel ifadeleri Tablo 2' de verilmiştir. Kullanılan kısıtlı ve kısıtsız kıyaslama fonksiyonlarının matematiksel ifadeleri Tablo 3' de gösterilmiştir.

Tablo 2. Mühendislik problemlerinin matematiksel gösterimi

\begin{tabular}{|c|c|c|}
\hline $\mathbf{F}$ & DEĞiŞKEN SINIRI & AMAÇ FONKSIYONLARI \\
\hline BEAM & $\begin{array}{c}\rho=\frac{7800 \mathrm{~kg}}{\mathrm{~m}^{3}}, P=1 \mathrm{kN}, \\
E=207 \mathrm{GPa} S_{y}=300 \mathrm{MPa}, \\
\delta \max =5 \mathrm{~mm}\end{array}$ & $\begin{array}{l}\operatorname{minf}_{1}(d, l)=\rho \frac{\pi d^{2}}{4} l \\
\operatorname{minf}_{2}(d, l)=\delta=\frac{64 P l^{3}}{3 E \pi d^{4}} \quad, \sigma_{\text {max }}=\frac{32 P l}{\pi d^{3}} \leq S_{y}\end{array}$ \\
\hline DISC & $\begin{array}{c}55 \leq x_{1} \leq 80 \\
75 \leq x_{2} \leq 110 \\
1000 \leq x_{3} \leq 3000 \\
2 \leq x_{4} \leq 20\end{array}$ & $\begin{array}{l}\min f_{1}(x)=4.9 e-5\left(x_{2}^{2}-x_{1}^{2}\right)\left(x_{4}-1\right) \\
\min _{2}(x)=(9.82 e 6) \frac{x_{2}^{2}-x_{1}^{2}}{x_{3} x_{4}\left(x_{2}^{3}-x_{1}^{3}\right)} \\
g_{1}=20+x_{1}-x_{2} \leq 0 \\
g_{2}=2.5\left(x_{4}+x_{1}\right)-30 \leq 0 \\
g_{3}=\frac{x_{3}}{3.14\left(x_{2}^{2}-x_{1}^{2}\right)^{2}}-0.4 \leq 0 \\
g_{4}=2.22 e-3 x_{3} \frac{x_{2}^{3}-x_{1}^{3}}{\left(x_{2}^{2}-x_{1}^{2}\right)^{2}}-1 \leq 0 \\
g_{5}=900-\left(\frac{2.66 e-2 x_{3} x_{4}\left(x_{3}^{3}-x_{1}^{3}\right)}{x_{2}^{2}-x_{1}^{2}}\right) \leq 0\end{array}$ \\
\hline FBTP & $\begin{array}{c}1 \leq x_{1}, x_{4} \leq 3 \\
\sqrt{2} \leq x_{2}, x_{3} \leq 3\end{array}$ & $\begin{array}{l}\operatorname{minf}_{1}(x)=L\left(2 x_{1}+\sqrt{2 x_{2}}+\sqrt{x_{3}}+x_{4}\right) \\
\operatorname{minf}_{2}(x)=\left(F \frac{L}{E}\right)\left(\frac{2}{x_{2}}+2 \frac{\sqrt{2}}{x_{2}}-2 \frac{\sqrt{2}}{x_{3}}+\frac{2}{x_{4}}\right)\end{array}$ \\
\hline GEAR & $12 \leq x_{1}, x_{2}, x_{3}, x_{4} \leq 60$ & $\begin{array}{l}\min f_{1}(x)=\left(\left(\frac{1}{6.931}\right)-\left(\frac{x_{1} x_{2}}{x_{3} x_{4}}\right)\right)^{2} \\
\min f_{2}(x)=\max \left(\left[x_{1}, x_{2}, x_{3}, x_{4}\right]\right)\end{array}$ \\
\hline
\end{tabular}


Tablo 3: Kısıtl1-kısıtsız kıyaslama fonksiyonlarının matematiksel gösterimi

\begin{tabular}{|c|c|c|}
\hline $\mathbf{F}$ & DEĞiŞKEN SINIRI & AMAÇ FONKSIYONLARI \\
\hline ZDT1 & $\begin{array}{c}x_{i} \in[0,1] \\
i=1, \ldots, n \\
n=30\end{array}$ & $\begin{array}{l}f_{1}(x)=x_{1} \\
f_{2}(x)=g(x)\left(-\sqrt{f_{1} / g(x)}\right) \\
g(x)=1+9\left(\sum_{i=2}^{m} x_{i}\right) /(n-1)\end{array}$ \\
\hline ZDT6 & $\begin{array}{l}x_{i} \in[0,1] \\
i=1, \ldots, n \\
n=10\end{array}$ & $\begin{array}{l}f_{1}(x)=1-\exp \left(-4 x_{1}\right) \sin ^{6}\left(\pi x_{1}\right) \\
f_{2}(x)=g(x)\left(1-\left(x_{1} / g(x)\right)^{2}\right) \\
g(x)=1+9\left[\left(\sum_{i=2}^{m} x_{i} /(n-1)\right)\right]^{0.25}\end{array}$ \\
\hline FON & $\begin{array}{c}x_{i} \in[-4,4] \\
i=1, \ldots, n \\
n=10\end{array}$ & $f_{1}(x)=1-\exp \left(-\sum_{1}^{3}\left(x_{i}-\frac{1}{\sqrt{3}}\right)^{2}\right)$ \\
\hline KUR & $\begin{array}{c}x_{i} \in[-5,5] \\
i=1, \ldots, n \\
n=3\end{array}$ & $\begin{array}{l}f_{1}(x)=\sum_{i=1}^{n-1}\left(-10 \exp \left(-0.2 \sqrt{x_{i}^{2}}+\sqrt{x_{i+1}^{2}}\right)\right) \\
f_{2}(x)=\sum_{i=1}^{n}\left(\left|x_{i}\right|^{0.8}+5 \sin x_{i}^{3}\right)\end{array}$ \\
\hline VIE & $\begin{array}{c}x_{i} \in[-3,3] \\
i=1, \ldots, n \\
n=2\end{array}$ & $\begin{array}{l}f_{1}(x)=0.5\left(x_{1}^{2}+x_{2}^{2}\right)+\sin \left(x_{1}^{2}+x_{2}^{2}\right) \\
f_{2}(x)=15+\frac{1}{8}\left(4+3 x_{1}-2 x_{2}\right)^{2}+\frac{1}{27}\left(1+x_{1}-x_{2}\right)^{2} \\
f_{3}(x)=\left(1+x_{1}^{2}+x_{2}^{2}\right)^{-1}-1.1 \exp \left(-x_{1}^{2}-x_{2}^{2}\right)\end{array}$ \\
\hline POLO & $\begin{array}{c}x_{i} \in[-\pi, \pi] \\
i=1, \ldots, n \\
n=2\end{array}$ & $\begin{array}{l}f_{1}(x)=\left[1+\left(A_{1}-B_{1}\right)^{2}+\left(A_{2}-B_{2}\right)^{2}\right] \\
f_{2}(x)=\left[\left(x_{1}+3\right)^{2}+\left(x_{2}+1\right)^{2}\right] \\
A_{1}=0.5 \sin 1-2 \cos 1+\sin 2-1.5 \cos 2 \\
A_{2}=1.5 \sin 1-\cos 1+2 \sin 2-0.5 \cos 2 \\
B_{1}=0.5 \sin x_{1}-2 \cos x_{1}+\sin x_{2}-1.5 \cos x_{2} \\
B_{2}=1.5 \sin x_{1}-\cos x_{1}+2 \sin x_{2}-0.5 \cos x_{2}\end{array}$ \\
\hline CNEX & $\begin{array}{c}x_{1} \in[0,11] \\
x_{2} \in[0,5]\end{array}$ & $\begin{array}{l}f_{1}(x)=x_{1} \\
f_{2}(x)=\left(1+x_{2}\right) / x_{1} \\
g_{1}(x)=9 x_{1}+x_{2} \geq 6 \\
g_{2}(x)=-x_{2}+9 x_{1} \geq 1\end{array}$ \\
\hline SRN & $\begin{array}{l}x_{1} \in[-20,20] \\
x_{2} \in[-20,20]\end{array}$ & $\begin{array}{l}f_{1}(x)=2+\left(x_{1}-2\right)^{2}+\left(x_{2}-2\right)^{2} \\
f_{2}(x)=9 x_{1}-\left(x_{2}-1\right) \\
g_{1}(x)=x_{1}^{2}+x_{2}^{2} \leq 225 \\
g_{2}(x)=x_{1}-3 x_{2}+10 \leq 0\end{array}$ \\
\hline BNH2 & $\begin{array}{c}x_{i} \in[-7,4] \\
i=1, \ldots, n \\
n=2\end{array}$ & $\begin{array}{l}f_{1}(x)=x_{1}^{2}-x_{2} \\
f_{2}(x)=-0.5 x_{1}-x_{2}-1 \\
g_{1}(x)=6.5-\frac{x_{1}}{6}-x_{2} \geq 0 \\
g_{2}(x)=7.5-\frac{x_{1}}{2}-x_{2} \geq 0 \\
g_{2}(x)=30+5 x_{1}-x_{2} \geq 0\end{array}$ \\
\hline CTP8 & $\begin{array}{c}x_{i} \in[0,1] \\
i=1, \ldots, n \\
n=2\end{array}$ & $\begin{array}{l}f_{1}(x)=x_{1} \\
f_{2}(x)=g(x)\left(1-\frac{f_{1}(x)}{g(x)}\right) \\
\begin{aligned} g(x) & =\cos (\theta)\left[f_{2}(x)-e\right]-\sin (\theta) x_{1} \\
& \geq a \mid \sin \left\{b \pi\left[\sin (\theta)\left(f_{2}(x)-e\right)\right.\right. \\
& \left.\left.+\cos (\theta) x_{1}\right]^{c}\right\}\left.\right|^{d}\end{aligned}\end{array}$ \\
\hline
\end{tabular}


Geliştirilen algoritmaların başarısını değerlendirmek için kullanılan ölçütlere performans ölçütleri denilmektedir. Çalışmamızda literatürde yer edinmiş ve çok amaçlı optimizasyon algoritmalarının karşılaştırılmasında sıç̧a kullanılan performans ölçütleri kullanılmıştır. Bunlar; Uzaklık Mesafesi (GD), Ters Uzaklık Mesafesi (RGD), Boşluk(S), Yayılma (SP) ve Maksimum Yayılma(MS) performans ölçüm metrikleridir.

\section{Uzaklık Mesafesi (GD):}

GD, 1998 yılında Veldhuizen tarafından önerilmiştir ve elde edilen çözümlerin, Pareto-optimal cephe arasındaki mesafelerin ölçümü ile hesaplanmaktadır [15]. $Q$, elde edilen çözüm seti ve $P$, Pareto optimal cephesinde baskın olmayan çözümler kümesi olsun. Bir $Q$ çözümün $P$ optimal çözüm kümesine ait olup olmadığ $1 Q$ ' nun $P$ ' ye olan ortalama uzaklığı ile belirlenmektedir. GD değeri Denklem 15 şeklinde hesaplanır [14,15]:

$G D=\frac{\left(\sum_{i=1}^{|Q|} d_{i}^{p}\right)^{1 / p}}{|Q|}$

$p=2$ için, $d_{i}$ parametresi $i \in Q$ çözümü ile $P$ 'nin en yakın üyesi arasındaki Denklem 16' da verilen (nesnel alanda) Öklid mesafesidir:

$d_{i}=\min _{k=1}|P| \sqrt{\sum_{m=1}^{M}\left(f_{m}^{i}-f_{m}^{k}\right)^{2}}$

Burada $f_{m}^{k}, P$ 'nin $k$. elemanının $m$. amaç fonksiyon değeridir.

\section{Ters Uzaklık Mesafesi (RGD):}

Ters uzaklık mesafesi (RGD), hem çeşitliliği hem de çözümleri birleştirerek hesaba katan GD'nin geliştirilmiş bir halidir. Bununla birlikte, çözümlerin Pareto-optimal cepheye en yakın ortalama mesafesini hesaplayan GD' nin aksine, Pareto-optimal cephedeki örnek noktaların elde edilen çözümlere en yakın ortalama mesafesini hesaplar. RGD hesaplama formülü Denklem 17' de verilmiştir.

$R G D=\frac{\left(\sum_{i=1}^{|P|} d_{i}^{Q}\right)^{1 / q}}{|P|}$

RGD' nin en büyük avantajı, çözümlerin hem yakınsamasını hem de çeşitliliğini aynı anda ölçebilmesidir. GD' ye benzer şekilde, RGD hedeflerin sayısı arttıkça katlanarak maliyetli hale gelmesidir [15].

\section{Maksimum Yayılma (MS)}

Zitzler (1999), denklem 18' de gösterildiği gibi baskın olmayan kümede gözlenen aşırı fonksiyon değerleri tarafından oluşturulan bir hiper kutunun köşegeninin uzunluğunu ölçen metrik tanımlamıştır [16]:

$D=\sqrt{\sum_{m=1}^{M}\left(\max _{i=1} f_{m}^{i}-\min _{i=1} f_{m}^{i}\right)}$

İki amaç problem için MS, amaç uzayındaki iki uç çözüm arasındaki Öklid mesafesini ifade etmektedir. Yukarıdaki metriğin normalleştirilmiş bir versiyonuna sahip olmak için, denklem 19 kullanılarak değiştirilebilir:

$\bar{D}=\sqrt{\frac{1}{M} \sum_{m=1}^{M}\left(\frac{\max _{i=1} f_{m}^{i}-\min _{i=1} f_{m}^{i}}{F_{m}^{\max }-F_{m}^{\min }}\right)^{2}}$

Burada, $F_{m}^{\max }$ ve $F_{m}^{\text {min }}$, seçilen Pareto-optimal çözüm setinin $(P) m$. hedefinin maksimum ve minimum değeridir. Bu şekilde, yukarıdaki metrik ile geniş çapta yayılmış bir dizi çözüm elde edilir. Bununla birlikte, ne $D$ ne de $\bar{D}$, ara çözeltilerin tam dağılımını değerlendiremez [14]. 


\section{Boşluk (S)}

Schott (1995), elde edilen baskın olmayan kümedeki ardışık çözümler arasındaki bağıl mesafe ölçüsünün hesaplanmasına dayalı olan metriği denklem 20' deki gibi önermiştir $[17,18]$ :

$S=\sqrt{\frac{1}{|Q|} \sum_{i=1}^{|Q|}\left(d_{i}-\bar{d}\right)^{2}}$

Burada, $d_{i}=\min _{k \in Q \wedge k \neq i} \sum_{i=1}^{M}\left|f_{i}^{m}-f_{i}^{k}\right|$ olmak üzere ve $\bar{d}=\sum_{i=1}^{|Q|} d_{i} / Q$ yukarıdaki mesafe ölçüsünün ortalama değeridir.

\section{Yayılma (SP)}

Yayılma derecesini dikkate almayan ölçümlerde, çözümler belli aralıklarda aynı sonucu ürettiği için Deb ve arkadaşları tarafından yayılma derecesini dikkate alan yeni bir metrik (Spread) geliştirilmiştir. Spread ölçütünün formülasyonu Denklem 21' de verilmektedir.

$\Delta=\frac{\sum_{m=1}^{M} d_{m}^{e}+\sum_{i=1}^{|Q|}\left|d_{i}-\bar{d}\right|}{\sum_{m=1}^{M} d_{m}^{e}+|Q| \bar{d}}$

Burada, $d_{i}$, komşu çözümler arasında herhangi bir mesafe ölçümü olabilir ve $\bar{d}$, bu mesafe ölçümlerinin ortalama değeridir. Öklid mesafesi veya kalabalık mesafesi $d_{i}$ ' yi hesaplamak için kullanılabilir. $d_{m}^{e}$ parametresi, $m$. hedef fonksiyonuna karşılık gelen $P^{*}$ ve $Q$ nin uç çözümleri arasındaki mesafedir [14].

Tablo 4' e bakıldığı zaman GD ölçütüne göre istatistiksel veriler görülmektedir. Sonuçlara göre F4, F6, F11, F13 ve F14 fonksiyonlarında MOGoldSA, F2 ve F10'da C8, F1 ve F12' de C1, F1' de C2, F3'te C7,F5'te C10 algoritmaları başarılı sonuçlar üretmiştir.

Tablo 4: GD ölçütüne göre istatistiksel sonuçlar (İ: istatistiksel, Ort: ortalama değer, M: MOGoldSA, C1C10: Kaotik haritalı MOGoldSA)

\begin{tabular}{|c|c|c|c|c|c|c|c|c|c|c|c|c|c|c|c|}
\hline$F$ & $\dot{I}$ & F1 & $\mathrm{F} 2$ & F3 & F4 & F5 & F6 & F7 & F8 & F9 & F10 & F11 & F12 & F13 & F14 \\
\hline \multirow{4}{*}{ M } & Ort & 0,0018 & 8,3199 & 0,0125 & 0,0116 & 0,1685 & 1,7130 & 0,0013 & $1,31 \mathrm{E}+05$ & 15,8700 & 0,2749 & 2,3918 & 0,0263 & 0,4963 & 0,8449 \\
\hline & $S t d$ & 0,0002 & 0,0753 & 0,0052 & 0,0034 & 0,1868 & 0,2213 & 0,0001 & $5,12 E+04$ & 0,1832 & 0,2072 & 0,8702 & 0,0167 & 1,1031 & 1,1038 \\
\hline & En iyi & 0,0015 & 8,1946 & 0,0054 & 0,0055 & 0,0522 & 1,2180 & 0,0011 & $6,71 \mathrm{E}+04$ & 15,3711 & 0,0314 & 0,8173 & 0,0050 & 0,0013 & 0,0003 \\
\hline & En kötü & 0,0029 & 8,4382 & 0,0256 & 0,0209 & 1,0355 & 2,0817 & 0,0014 & $2,80 E+05$ & 16,1202 & 0,6265 & 4,3257 & 0,0715 & 3,1007 & 3,2217 \\
\hline \multirow{4}{*}{$\mathrm{C} 1$} & Ort & 0,0019 & 8,3330 & 0,0159 & 0,0169 & 0,2150 & 7,2059 & 0,0013 & $1,19 E+05$ & 15,7261 & 0,3725 & 5,8174 & 0,0258 & 1,6759 & 1,3003 \\
\hline & Std & 0,0006 & 0,1054 & 0,0143 & 0,0166 & 0,3487 & 28,6789 & 0,0001 & $4,37 E+04$ & 0,2125 & 0,1954 & 14,6580 & 0,0150 & 1,4865 & 1,2621 \\
\hline & En iyi & 0,0014 & 8,1074 & 0,0069 & 0,0060 & 0,0687 & & ,0011 & $49 E+04$ & & 0328 & 1,2962 & 0,0071 & 0,0011 & 0,0002 \\
\hline & En kötü & 0,0050 & 8,5934 & 0,0854 & 0,0924 & 1,9866 & 159,0466 & 0,0017 & $2,22 E+05$ & 16,0554 & 0,8270 & 82,9411 & 0,0568 & 3,3801 & 3,1894 \\
\hline \multirow{4}{*}{$\mathrm{C} 2$} & Ort & 0,0017 & 8,3000 & 0,0139 & 0,0170 & 0,2588 & 1,9341 & 0,0013 & $1,32 \mathrm{E}+05$ & 15,7143 & 0,3311 & 2,8275 & 0,0288 & 2,4400 & 1,2334 \\
\hline & Std & 0,0002 & 0,1021 & 0,0107 & 0,0148 & 0,4427 & 0,2131 & 0,0002 & $4,85 E+04$ & 0,2152 & 0,2146 & 1,4607 & 0,0197 & 1,1341 & 1,3320 \\
\hline & En iyi & 0,0014 & 8,0520 & 0,0054 & 0,0054 & 0,0691 & 1,4358 & 0,0011 & $3,86 \mathrm{E}+04$ & 15,2487 & 0,0402 & 1,2939 & 0,0075 & 0,0012 & 0,0003 \\
\hline & En kötü & 0,0020 & 8,5105 & 0,0649 & 0,0627 & 2,3990 & 2,4182 & 0,0021 & $2,62 E+05$ & 16,0393 & 0,6688 & 7,4301 & 0,0806 & 3,3788 & 3,3160 \\
\hline \multirow{4}{*}{ C3 } & Ort & 0,0017 & 8,3072 & 0,0145 & 0,0153 & 0,1837 & 1,9951 & 0,0013 & $1,42 E+05$ & 15,7096 & 0,4276 & 3,2260 & 0,0333 & 1,6831 & 1,1971 \\
\hline & Std & 0,0002 & 0,1035 & 0,0080 & 0,0104 & 0,1874 & 0,2184 & 0,0001 & $7,41 E+04$ & 0,2438 & 0,2060 & 1,4267 & 0,0187 & 1,4813 & 0,9893 \\
\hline & En iyi & 0,0013 & 8,0450 & 0,0060 & 0,0005 & 0,0615 & 1,5117 & 0,0011 & $5,57 \mathrm{E}+04$ & 15,2326 & 0,0420 & 1,2835 & 0,0080 & 0,0009 & 0,0002 \\
\hline & En kötü & 0,0022 & 8,4974 & 0,0484 & 0,0479 & 0,9753 & & 0,0018 & $3,56 \mathrm{E}+05$ & 16,1635 & 0,9420 & 7,4359 & 0,0788 & 3,4575 & 2,8035 \\
\hline \multirow{4}{*}{$\mathrm{C} 4$} & Ort & 0,0017 & 8,3224 & 0,0126 & 0,0135 & 0,2078 & 1,8997 & 0,0013 & $1,21 \mathrm{E}+05$ & 15,7494 & 0,3857 & 3,1026 & 0,0296 & 1,2962 & 1,2515 \\
\hline & Std & 0,0002 & 0,0975 & 0,0043 & 0,0039 & 0,1737 & 0,2272 & 0,0001 & $4,65 E+04$ & 0,1634 & 0,1700 & 1,3081 & 0,0166 & 1,5032 & 1,0860 \\
\hline & En iyi & 0,0014 & 8,1365 & 0,0062 & 0,0075 & 0,0595 & 1,3834 & 0,0012 & $5,54 \mathrm{E}+04$ & 15,3458 & 0,0444 & 1,1690 & 0,0072 & 0,0014 & 0,0003 \\
\hline & En kötü & 0,0021 & 8,6426 & 0,0218 & 0,0218 & 0,9515 & 2,2765 & 0,0019 & $2,51 E+05$ & 15,9880 & 0,6818 & 5,2628 & 0,0788 & 3,3679 & 3,0271 \\
\hline \multirow{4}{*}{ C5 } & Ort & 0,0017 & 8,3130 & 0,0174 & 0,0134 & 0,2096 & 6,3460 & 0,0013 & $1,29 \mathrm{E}+05$ & 15,7213 & 0,3469 & 3,0392 & 0,0384 & 1,8277 & 1,1596 \\
\hline & $S t d$ & 0,0002 & 0,0999 & 0,0184 & 0,0076 & 0,2281 & 24,2520 & 0,0001 & $5,43 E+04$ & 0,2565 & 0,1923 & 1,6124 & 0,0230 & 1,5230 & 1,1629 \\
\hline & En iyi & 0,0014 & 8,1101 & 0,0069 & 0,0058 & 0,0710 & 1,5239 & 0,0011 & $4,88 \mathrm{E}+04$ & 15,2398 & 0,0323 & 0,6782 & 0,0157 & 0,0011 & 0,0003 \\
\hline & En kötü & 0,0023 & 8,4549 & 0,1065 & 0,0482 & 1,1356 & 134,7480 & 0,0014 & $2,71 \mathrm{E}+05$ & 16,1714 & 0,6920 & 7,2247 & 0,1099 & 3,3499 & 3,1608 \\
\hline \multirow{4}{*}{ C6 } & Ort & 0,0018 & 8,3031 & 0,0175 & 0,0163 & 0,2324 & 1,9527 & 0,0013 & $1,16 E+05$ & 15,7738 & 0,3600 & 2,9896 & 0,0270 & 1,9851 & 1,0787 \\
\hline & Std & 0,0001 & 0,0743 & 0,0140 & 0,0143 & 0,4670 & 0,2523 & 0,0001 & $4,55 E+04$ & 0,1933 & 0,2230 & 1,3382 & 0,0160 & 1,4361 & 1,2147 \\
\hline & En iyi & 0,0015 & 8,1373 & 0,0073 & 0,0065 & 0,0774 & 1,5239 & 0,0012 & $5,92 \mathrm{E}+04$ & 15,3255 & 0,0319 & 1,3425 & 0,0075 & 0,0011 & 0,0003 \\
\hline & En kötü & 0,0019 & 8,5119 & 0,0660 & 0,0822 & 2,6451 & 2,3934 & 0,0015 & $2,16 \mathrm{E}+05$ & 16,0716 & 0,7712 & 7,2247 & 0,0812 & 3,2526 & 3,8606 \\
\hline
\end{tabular}


Tablo 4: GD ölçütüne göre istatistiksel sonuçlar (devam)

\begin{tabular}{|c|c|c|c|c|c|c|c|c|c|c|c|c|c|c|c|}
\hline$F$ & $\dot{I}$ & F1 & $\mathrm{F} 2$ & F3 & $\mathrm{F} 4$ & F5 & F6 & F7 & F8 & F9 & F10 & F11 & F12 & F13 & F14 \\
\hline \multirow{4}{*}{$\mathrm{C} 7$} & Ort & 0,0017 & 8,3250 & 0,0124 & 0,0146 & 0,1510 & 1,9204 & 0,0013 & $1,29 E+05$ & 15,8390 & 0,3242 & 2,8455 & 0,0308 & 1,5177 & 1,0963 \\
\hline & Std & 0,0002 & 0,1300 & 0,0052 & 0,0119 & 0,1097 & 0,2254 & 0,0001 & $6,08 E+04$ & 0,1614 & 0,2086 & 1,2679 & 0,0194 & 1,5178 & 1,1465 \\
\hline & En iyi & 0,0013 & 8,0018 & 0,0054 & 0,0067 & 0,0572 & 1,4960 & 0,0012 & $5,14 \mathrm{E}+04$ & 15,3908 & 0,0386 & 0,7718 & 0,0068 & 0,0016 & 0,0002 \\
\hline & En kötü & 0,0020 & 8,5596 & 0,0311 & 0,0692 & 0,5553 & 2,3802 & 0,0015 & $3,43 E+05$ & 16,0761 & 0,6123 & 6,4154 & 0,0889 & 3,5994 & 3,4080 \\
\hline \multirow{4}{*}{$\mathrm{C} 8$} & Ort & 0,0017 & 8,2322 & 0,0153 & 0,0121 & 0,1414 & 7,2071 & 0,0013 & $1,32 \mathrm{E}+05$ & 15,7590 & 0,2902 & 3,0378 & 0,0316 & 1,8527 & 0,7797 \\
\hline & Std & 0,0002 & 0,4424 & 0,0130 & 0,0046 & 0,0522 & 29,0651 & 0,0001 & $6,55 E+04$ & 0,2336 & 0,2186 & 1,3643 & 0,0177 & 1,4415 & 0,9194 \\
\hline & En iyi & 0,0014 & 5,9419 & 0,0052 & 0,0052 & 0,0503 & 1,6029 & 0,0012 & $4,35 E+04$ & 15,2692 & 0,0265 & 1,2403 & 0,0058 & 0,0010 & 0,0003 \\
\hline & En kötü & 0,0020 & 8,5686 & 0,0690 & 0,0225 & 0,2687 & 161,0950 & 0,0016 & $2,59 \mathrm{E}+05$ & 16,1254 & 0,8765 & 6,9020 & 0,0636 & 3,3179 & 3,6920 \\
\hline \multirow{4}{*}{ C9 } & Ort & 0,0017 & 8,3052 & 0,0141 & 0,0193 & 0,1860 & 1,9214 & 0,0013 & $1,40 E+05$ & 15,8101 & 0,2927 & 2,9073 & 0,0257 & 1,6732 & 1,1073 \\
\hline & Std & 0,0002 & 0,0949 & 0,0115 & 0,0249 & 0,1106 & 0,2409 & 0,0001 & $5,33 E+04$ & 0,1931 & 0,2216 & 1,4787 & 0,0126 & 1,4927 & 1,2232 \\
\hline & En iyi & 0,0015 & 8,1119 & 0,0062 & 0,0048 & 0,0592 & 1,4999 & 0,0012 & $7,38 E+04$ & 15,3524 & 0,0367 & 0,8607 & 0,0092 & 0,0008 & 0,0003 \\
\hline & En kötü & 0,0022 & 8,4867 & 0,0695 & 0,1192 & 0,5561 & 2,4462 & 0,0016 & $2,72 E+05$ & 16,1674 & 0,8550 & 7,0791 & 0,0533 & 3,2864 & 3,1565 \\
\hline \multirow{4}{*}{$\mathrm{C} 10$} & Ort & 0,0017 & 8,3093 & 0,0135 & 0,0178 & 0,1308 & 6,2348 & 0,0013 & $1,30 E+05$ & 15,7671 & 0,3876 & 3,1695 & 0,0266 & 2,0185 & 0,9141 \\
\hline & Std & 0,0002 & 0,1225 & 0,0071 & 0,0202 & 0,0852 & 19,2587 & 0,0001 & $5,99 E+04$ & 0,2583 & 0,2258 & 1,9354 & 0,0150 & 1,4648 & 1,0745 \\
\hline & En iyi & 0,0015 & 8,0122 & 0,0050 & 0,0061 & 0,0537 & 1,4231 & 0,0012 & $4,24 E+04$ & 15,2144 & 0,0373 & 1,1664 & 0,0103 & 0,0016 & 0,0003 \\
\hline & En kötü & 0,0023 & 8,4963 & 0,0427 & 0,0967 & 0,5213 & 104,7439 & 0,0017 & $2,72 E+05$ & 16,1108 & 0,8129 & 9,5690 & 0,0612 & 3,6282 & 3,1713 \\
\hline
\end{tabular}

Tablo 5' te RGD ölçütüne göre istatistiksel veriler yer almaktadır. Ortalama sonuçlarına göre F1, F3, F4, F6,F7, F10-F13 fonksiyonlarında MOGoldSA diğerlerine göre üstün performans sergilemiștir. F2 ve F14'te C8, F5'te C7, F9' da ise C9 kaotik haritalı MOGoldSA algoritmaları başarılı sonuçlar üretmiştir.

Tablo 5: RGD ölçütüne göre istatistiksel sonuçlar (İ: istatistiksel, Ort: ortalama değer, M: MOGoldSA, C1C10: Kaotik haritalı MOGoldSA)

\begin{tabular}{|c|c|c|c|c|c|c|c|c|c|c|c|c|c|c|c|}
\hline$F$ & $\dot{I}$ & F1 & $\mathrm{F} 2$ & F3 & $\mathrm{F} 4$ & F5 & F6 & F7 & F8 & F9 & F10 & F11 & F12 & F13 & F14 \\
\hline \multirow{4}{*}{ M } & Ort & 0,0139 & 8,6256 & 0,0911 & 0,0971 & 0,1540 & 5,5666 & 0,0066 & $7,85 E+04$ & 15,0890 & 0,1900 & 3,4931 & 0,1076 & 0,7300 & 0,2182 \\
\hline & Std & 0015 & 0,0059 & 0,0219 & 0,0300 & 0391 & 0,4415 & 0006 & $3,20 E+04$ & 0,1908 &, 0413 & ,9362 &, 0415 & , ,8493 & , 3521 \\
\hline & En iyi & 0,0113 & 8,6062 & 0,0688 & 0,0606 & 0,0899 & 4,7980 & 0,0057 & $5,30 E+04$ & 14,8700 & 0,1304 & 1,7486 & 0,0596 & 0,0063 & 0,0065 \\
\hline & En kötü & 0,0174 & 8,6319 & 0,1681 & 0,1843 & 0,2526 & 6,6794 & 0078 & $2,10 E+05$ & 15,5397 & 0,2964 & 5,7345 & 2540 &, 5414 & 1,0779 \\
\hline \multirow{4}{*}{$\mathrm{C} 1$} & Ort & 0,0155 & 8,6213 & 0,1162 & 0,1476 & 0,1630 & 6,2062 & 0099 & $7,69 E+04$ & 15,0457 & 0,2315 & 8,0721 & 1277 & 1,3935 & 0,4091 \\
\hline & Std & 0,0020 & 0,0276 & 0,0438 & 0,0879 & 0,0412 & 0,7296 & 0,0021 & $1,88 \mathrm{E}+04$ & 0,1794 & 0,0669 & 20,8885 & 0,0552 & 1,1752 & 0,4266 \\
\hline & En iyi & 0,0118 & 8,4773 & 0,0674 & 0,0775 & 0,1057 & 5,2851 & 0,0068 & $5,58 \mathrm{E}+04$ & 14,8746 & 0,1370 & 2,1990 & 0,0702 & 0,0092 & 0,0075 \\
\hline & En kötü & 0,0216 & 8,6322 & 0,2693 & 0,5136 & 0,3149 & 7,8554 & 0,0160 & $1,63 E+05$ & 15,5230 & 0,4027 & 118,2144 & 0,2879 & 2,7222 & 1,0075 \\
\hline \multirow{4}{*}{$\mathrm{C} 2$} & Ort & D161 & 6246 & 0,1094 & 0,1343 & 614 & 6,4102 & 101 & $62 E+04$ & 15,0656 & 0,2269 & 3342 & 1232 & 0541 & 0,3461 \\
\hline & Std & 0,0021 & 0,0079 & 0,0302 & 0,0527 & 0,0281 & 1,2850 & 0,0016 & $2,01 E+04$ & 0,1969 & 0,0680 & 2,5655 & 0,0350 & 0,9401 & 0,3845 \\
\hline & En iyi & 0,0125 & 8,6016 & 0,0643 & 0,0629 & 0,1225 & 4,8798 & 0070 & $5,37 E+04$ & 14,8552 & 0,1343 & 1,8702 & 0738 & 0103 & 0,0075 \\
\hline & En kötü & 0,0211 & 8,6323 & 0,1954 & 0,2862 & 0,2225 & 11,7756 & 0,0146 & $1,34 \mathrm{E}+05$ & 15,4928 & 0,3830 & 15,4309 & 0,2240 & 2,8145 & 0,9632 \\
\hline \multirow{4}{*}{ C3 } & Ort & 0166 & 8,6223 & 0,1198 & 0,1674 & 1759 & 6,5419 & 107 & $8,54 \mathrm{E}+04$ & 15,0878 & 0,2263 & 5,1722 & 1252 & 4867 & 0,2957 \\
\hline & Std & 0,0027 & 0,0097 & 0,0321 & 0,2402 & 0,0540 & 1,8062 & 0,0027 & $2,69 \mathrm{E}+04$ & 0,2201 & 0,0769 & 2,0466 &, 0370 & 1,1225 & 0,3315 \\
\hline & En iyi & 0,0119 & 8,6010 & 0,0706 & 0,0743 & 0,0896 & 5,1555 & 0,0078 & $5,40 E+04$ & 14,8501 & 0,1156 & 2,8164 &, 0657 & 0,0101 & 0,0072 \\
\hline & En kötü & 0,0249 & 8,6325 & 0,2056 & 1,4144 & 0,3755 & 15,3156 & 0,0211 & $1,77 E+05$ & 15,5536 & 0,5396 & 9,8725 & 297 & 2,6372 & 0,8605 \\
\hline \multirow{4}{*}{$\mathrm{C} 4$} & Ort & 0,0169 & 8,6183 & 0,1172 & 0,1058 & 0,1619 & 6,5518 & 0,0103 & $7,67 E+04$ & 15,0621 & 0,2405 & 4,5582 & 1283 & 1,2300 & 0,3716 \\
\hline & $S t d$ & & & 0,03 & & & & & $34 E+04$ & & & 1,7841 & 382 & 2001 & 0,3383 \\
\hline & En iyi & 0,0130 & 8,4593 & 0,0693 & 0,0706 & 0,1179 & 5,3827 & 0,0079 & $4,96 E+04$ & 14,8735 & 0,1323 & 1,9375 &, 0737 & 0,0092 & 0,0072 \\
\hline & En kötü & 0,0248 & 8,6320 & 0,2543 & 0,2196 & 0,2259 & 9,9374 & 0163 & $1,44 E+05$ & 15,5271 & 0,5116 & 9,7067 & 2119 & 2,9509 & 0,9038 \\
\hline \multirow{4}{*}{ C5 } & Ort & 0164 & 8,6202 & 0,1289 & 0,1118 & 0,1703 & 6,4240 & 0100 & $7,98 \mathrm{E}+04$ & 15,0455 & & 4,2867 & 274 & 1,5668 & 0,3183 \\
\hline & Std & 0,0020 & 0,0143 & 0,0508 & 0,0236 & 0,0360 & 1,2863 & 0,0033 & $1,91 \mathrm{E}+04$ & 0,1716 & 0,0539 & 1,6461 & 0,0417 & 1,2474 & 0,3736 \\
\hline & En iyi & 0,0130 & 8,5827 & 0,0818 & 0,0658 & 0,1202 & 4,8713 & 0,0064 & $5,33 E+04$ & 14,8770 & 0,1570 & 2,1506 &, 0646 & 0,0092 & 0,0077 \\
\hline & En kötü & 0,0201 & 8,6322 & 0,3482 & 0,1742 & 0,2478 & 11,4886 & 0,0238 & $1,30 \mathrm{E}+05$ & 15,5120 & 0,3670 & 9,7562 & 0,2119 & 2,7386 & 0,9388 \\
\hline \multirow{4}{*}{ C6 } & Ort & 0,0154 & 8,6193 & 0,1344 & 0,1349 & 0,1651 & 6,1323 & 0,0105 & $8,07 E+04$ & 15,1242 & 0,2379 & 4,6993 & 266 & 1,6873 & 0,2806 \\
\hline & Std & 0,0020 & 0,0221 & 0,1014 & 0,0707 & 0,0351 & 0,5991 & 0,0023 & $2,27 E+04$ & 0,2256 & 0,0772 & 1,9218 & ,0475 & 1,1153 & 0,3616 \\
\hline & En iyi & 0,0119 & 8,5240 & 0,0675 & 0,0659 & 0,1237 & 5,0300 & 0,0068 & $5,24 E+04$ & 14,8659 & 0,1231 & 2,1506 & 0771 & 0,0090 & 0,0073 \\
\hline & En kötü & 0,0187 & 8,6319 & 0,6048 & 0,4270 & 0,2880 & 7,4870 & 0,0152 & $1,31 E+05$ & 15,5606 & 0,4514 & 9,7562 & 0,2918 & 2,7826 & 1,1942 \\
\hline \multirow{4}{*}{$\mathrm{C} 7$} & Ort & 0,0162 & 8,6202 & 0,1060 & 0,1172 & 0,1521 & 6,5014 & 0,0104 & $8,71 \mathrm{E}+04$ & 15,1280 & 0,2549 & 5,4017 & 0,1256 & 1,3254 & 0,2778 \\
\hline & $S t d$ & 0,0024 & 0,0210 & 0,0218 & 0,0310 & 0,0243 & 2,0238 & 0,0037 & $3,94 E+04$ & 0,1866 & 0,1115 & 3,2640 & 0,0375 & 1,1795 & 0,3254 \\
\hline & En iyi & 0,0119 & 8,5378 & 0,0666 & 0,0683 & 0,1094 & 5,2940 & 0,0072 & $4,82 E+04$ & 14,8742 & 0,1161 & 2,0353 & 0,0850 & 0,0096 & 0,0065 \\
\hline & En kötü & 0,0226 & 8,6344 & 0,1560 & 0,2132 & 0,2015 & 15,7028 & 0,0274 & $2,52 E+05$ & 15,5380 & 0,6373 & 17,8493 & 0,2409 & 2,8171 & 0,8939 \\
\hline \multirow{4}{*}{$\mathrm{C} 8$} & Ort & 0,0159 & 8,5112 & 0,1179 & 0,1093 & 0,1657 & 6,9378 & 0,0102 & $8,30 E+04$ & 15,0838 & 0,2180 & 4,5841 & 0,1328 & 1,5990 & 0,1785 \\
\hline & Std & 0,0026 & 0,6060 & 0,0412 & 0,0316 & 0,0242 & 5,1348 & 0,0020 & $2,61 E+04$ & 0,1795 & 0,0557 & 1,8419 & 0,0518 & 1,1549 & 0,2730 \\
\hline & En iyi & 0,0115 & 5,3035 & 0,0604 & 0,0750 & 0,1310 & 5,2226 & 0,0071 & $5,29 E+04$ & 14,8677 & 0,1013 & 2,7531 & 0,0701 & 0,0103 & 0,0068 \\
\hline & En kötü & 0,0223 & 8,6314 & 0,2435 & 0,2116 & 0,2314 & 33,9452 & 0,0168 & $1,58 \mathrm{E}+05$ & 15,4704 & 0,3321 & 12,1250 & 0,2930 & 2,8010 & 0,9023 \\
\hline
\end{tabular}


Tablo 5: RGD ölçütüne göre istatistiksel sonuçlar (devamı...)

\begin{tabular}{|c|c|c|c|c|c|c|c|c|c|c|c|c|c|c|c|}
\hline$F$ & $\dot{I}$ & F1 & $\mathrm{F} 2$ & F3 & $\mathrm{F} 4$ & F5 & F6 & F7 & F8 & F9 & F10 & F11 & F12 & F13 & F14 \\
\hline \multirow{4}{*}{ C9 } & Ort & 0,0163 & 8,6220 & 0,1400 & 0,1457 & 0,1699 & 6,2038 & 0,0099 & $7,07 E+04$ & 15,0803 & 0,2390 & 4,6640 & 0,1286 & 1,4906 & 0,3594 \\
\hline & Std & 0,0022 & 0,0163 & 0,1260 & 0,1006 & 0,0348 & 0,7780 & 0,0016 & $1,52 \mathrm{E}+04$ & 0,1982 & 0,0884 & 1,9294 & 0,0419 & 1,2312 & 0,3994 \\
\hline & En iyi & 0,0130 & 8,5470 & 0,0714 & 0,0676 & 0,1208 & 4,8604 & 0,0079 & $5,05 E+04$ & 14,8699 & 0,1326 & 2,0254 & 0,0718 & 0,0084 & 0,0066 \\
\hline & En kötü & 0,0230 & 8,6316 & 0,7894 & 0,5954 & 0,2780 & 8,6924 & 0,0145 & $1,24 \mathrm{E}+05$ & 15,5507 & 0,5094 & 9,0899 & 0,2165 & 2,9830 & 1,0989 \\
\hline \multirow{4}{*}{$\mathrm{C} 10$} & Ort & 0,0162 & 8,6149 & 0,1245 & 0,1374 & 0,1672 & 7,8045 & 0,0095 & $7,96 \mathrm{E}+04$ & 15,0610 & 0,2502 & 4,9901 & 0,1315 & 1,7508 & 0,2642 \\
\hline & Std & 0,0024 & 0,0419 & 0,0640 & 0,0999 & 0,0444 & 5,7384 & 0,0016 & $2,35 E+04$ & 0,1844 & 0,0854 & 2,6161 & 0,0394 & 1,1106 & 0,3529 \\
\hline & En iyi & 0,0119 & 8,4077 & 0,0630 & 0,0815 & 0,1169 & 5,0802 & 0,0071 & $5,19 E+04$ & 14,8648 & 0,1520 & 2,0205 & 0,0697 & 0,0096 & 0,0073 \\
\hline & En kötü & 0,0216 & 8,6324 & 0,3562 & 0,6313 & 0,2870 & 33,3053 & 0,0136 & $1,36 \mathrm{E}+05$ & 15,5522 & 0,5657 & 14,7089 & 0,2183 & 2,7814 & 0,9537 \\
\hline
\end{tabular}

Tablo 6' da MS ölçütüne göre istatistiksel veriler yer almaktadır. Ortalama sonuçlarına göre F1, F9 ve F12' de C6, F7, F8 ve F11 fonksiyonlarında C7 iyi performans sergilerken, F3 ve F5 fonksiyonlarında C10, F10 ve F13 fonksiyonlarında ise MOGoldSA optimuma yakın sonuçlar üretmeyi başarmıştır.

Tablo 6: MS ölçütüne göre istatistiksel sonuçlar (İ: istatistiksel, Ort: ortalama değer, M: MOGoldSA, C1C10: Kaotik haritalı MOGoldSA)

\begin{tabular}{|c|c|c|c|c|c|c|c|c|c|c|c|c|c|c|c|}
\hline$F$ & $\dot{I}$ & F1 & $\mathrm{F} 2$ & F3 & $\mathrm{F} 4$ & F5 & F6 & F7 & F8 & F9 & F10 & F11 & F12 & F13 & F14 \\
\hline \multirow{4}{*}{ M } & Ort & 2,6048 & 15,8942 & 7,3048 & 7,4875 & 15,6436 & 550,3116 & 1,3844 & $1,19 \mathrm{E}+07$ & 12,8344 & 31,1862 & 279,4438 & 8,4128 & 1,0207 & 3,0685 \\
\hline & $S t d$ & 0,0190 & 0,1997 & 0,6430 & 0,5528 & 2,0664 & 3,3891 & 0,0053 & $9,30 E+05$ & 0,0953 & 1,6925 & 16,5129 & 0,0496 & 0,9002 & 1,9061 \\
\hline & En iyi & 2,5619 & 15,2051 & 5,5762 & 5,4992 & 14,5267 & 542,8399 & 1,3669 & $9,95 \mathrm{E}+06$ & 12,5153 & 28,5832 & 243,6088 & 8,3217 & 0,0187 & 1,1661 \\
\hline & En kötü & 2,6480 & 16,1176 & 8,0135 & 7,9759 & 24,2854 & 553,5211 & 1,3893 & $1,28 \mathrm{E}+07$ & 12,9014 & 34,0843 & 305,4576 & 8,5017 & 2,9087 & 6,2892 \\
\hline \multirow{4}{*}{$\mathrm{C} 1$} & Ort & 2,5802 & 15,8971 & 7,2520 & 6,9349 & 15,4176 & 578,5798 & 1,3701 & $1,20 E+07$ & 12,8495 & 31,5682 & 274,6033 & 8,4252 & 1,9431 & 3,3885 \\
\hline & Std & 0,0465 & 0,1989 & 0,6658 & 0,9021 & 1,8261 & 146,2923 & 0,0216 & $8,02 E+05$ & 0,0707 & 1,2712 & 29,0575 & 0,0597 & 0,7807 & 1,9081 \\
\hline & En iyi & 2,4657 & 15,4548 & 5,2635 & 4,4843 & 14,5242 & 545,3551 & 1,2927 & $1,02 \mathrm{E}+07$ & 12,6047 & 28,7205 & 141,5169 & 8,2953 & 0,0567 & 1,1475 \\
\hline & En kötü & 2,6718 & 16,1198 & 7,9522 & 7,9497 & 22,6497 & 1353,0341 & 1,3889 & $1,28 \mathrm{E}+07$ & 12,8977 & 33,2183 & 305,6006 & 8,5017 & 3,3600 & 8,1067 \\
\hline \multirow{4}{*}{$\mathrm{C} 2$} & Ort & 2,5869 & 15,8124 & 7,3035 & 7,0703 & 16,2571 & 549,8367 & 1,3741 & $1,20 \mathrm{E}+07$ & 12,8351 & 31,3849 & 276,6534 & 8,4089 & 2,2793 & 3,3286 \\
\hline & $S t d$ & 0,0596 & 0,4183 & 0,6012 & 0,7048 & 3,3396 & 7,4998 & 0,0172 & $8,17 \mathrm{E}+05$ & 0,1044 & 1,6655 & 16,6448 & 0,0704 & 0,6598 & 2,3312 \\
\hline & En iyi & 2,3713 & 13,9126 & 5,7275 & 5,2423 & 14,4483 & 528,5836 & 1,3156 & $1,02 \mathrm{E}+07$ & 12,3891 & 28,5490 & 222,0262 & 8,2497 & 1,3147 & 1,1506 \\
\hline & En kötü & 2,6327 & 16,1244 & 7,9966 & 7,9677 & 29,6872 & 553,5387 & 1,3891 & $1,28 \mathrm{E}+07$ & 12,8967 & 34,0964 & 295,3651 & 8,5022 & 3,4928 & 8,6117 \\
\hline \multirow{4}{*}{ C3 } & Ort & 2,5920 & 15,8391 & 7,2041 & 6,9043 & 15,5402 & 551,0465 & 1,3653 & $1,19 E+07$ & 12,8372 & 31,7141 & 267,0346 & 8,4020 & 1,8115 & 4,3031 \\
\hline & Std & 0,0385 & 0,2676 & 0,6462 & 1,4978 & 1,8479 & 5,4147 & 0,0240 & $8,46 \mathrm{E}+05$ & 0,0725 & 1,4793 & 20,4488 & 0,0891 & 0,8927 & 2,0126 \\
\hline & En iyi & 2,4775 & 15,0617 & 5,4842 & 0,5947 & 14,1275 & 531,4326 & 1,2599 & $1,04 \mathrm{E}+07$ & 12,6276 & 28,7927 & 232,6369 & 8,1755 & 0,0209 & 1,1602 \\
\hline & En kötü & 2,6235 & 16,1017 & 7,9357 & 8,0183 & 22,2433 & 553,5310 & 1,3873 & $1,28 \mathrm{E}+07$ & 12,8994 & 33,8330 & 307,4832 & 8,5016 & 3,2693 & 9,5035 \\
\hline \multirow{4}{*}{$\mathrm{C} 4$} & Ort & 2,6009 & 15,8667 & 7,2173 & 7,3819 & 16,0301 & 545,4246 & 1,3744 & $1,18 \mathrm{E}+07$ & 12,8390 & 31,5710 & 273,5217 & 8,3969 & 1,6280 & 3,6766 \\
\hline & $S t d$ & 0,0325 & 0,2758 & 0,5802 & 0,4494 & 1,8429 & 16,0517 & 0,0157 & $8,46 E+05$ & 0,0645 & 1,5637 & 16,4413 & 0,0832 & 0,9637 & 2,1020 \\
\hline & En iyi & 2,4731 & 15,1088 & 5,5466 & 6,2653 & 14,7046 & 485,4137 & 1,3205 & $1,04 \mathrm{E}+07$ & 12,6668 & 27,6263 & 246,8166 & 8,1876 & 0,0397 & 1,1647 \\
\hline & En kötü & 2,6237 & 16,1122 & 7,9918 & 7,9448 & 21,8766 & 553,4758 & 1,3898 & $1,28 \mathrm{E}+07$ & 12,8978 & 33,5374 & 306,9914 & 8,5016 & 3,6670 & 8,6138 \\
\hline \multirow{4}{*}{ C5 } & Ort & 2,5893 & 15,8672 & 7,1013 & 7,3029 & 15,8672 & 575,3540 & 1,3693 & $1,18 \mathrm{E}+07$ & 12,8566 & 31,5961 & 276,6824 & 8,4290 & 2,0600 & 3,4141 \\
\hline & Std & 0,0392 & 0,2890 & 0,6116 & 0,4903 & 2,3206 & 138,7188 & 0,0246 & $8,00 E+05$ & 0,0501 & 1,4614 & 15,1228 & 0,0688 & 0,8149 & 2,2299 \\
\hline & En iyi & 2,4897 & 14,6790 & 5,9712 & 6,0202 & 14,3456 & 514,7806 & 1,2632 & $1,04 \mathrm{E}+07$ & 12,7271 & 28,7932 & 259,2323 & 8,2727 & 0,0370 & 1,1508 \\
\hline & En kötü & 2,6236 & 16,1199 & 7,9602 & 7,9519 & 23,4614 & 1308,5832 & 1,3885 & $1,28 \mathrm{E}+07$ & 12,9007 & 33,3065 & 309,0974 & 8,5014 & 4,0221 & 8,9736 \\
\hline \multirow{4}{*}{ C6 } & Ort & 2,5784 & 15,9021 & 7,2224 & 7,0197 & 15,9135 & 551,3852 & 1,3683 & $1,18 \mathrm{E}+07$ & 12,7894 & 31,4504 & 269,4132 & 8,3957 & 1,9611 & 3,4703 \\
\hline & $S t d$ & 0,0497 & 0,2037 & 0,6065 & 0,8262 & 3,0200 & 3,1412 & 0,0209 & $8,45 E+05$ & 0,1660 & 1,5049 & 15,7129 & 0,0657 & 0,8602 & 2,1715 \\
\hline & En iyi & 2,4129 & 15,4294 & 5,3703 & 4,8267 & 14,5152 & 541,4408 & 1,3031 & $1,02 \mathrm{E}+07$ & 12,1394 & 28,7932 & 239,0199 & 8,2478 & 0,0169 & 1,1646 \\
\hline & En kötü & 2,6236 & 16,1217 & 7,9714 & 7,9785 & 30,3976 & 553,5392 & 1,3885 & $1,28 \mathrm{E}+07$ & 12,8981 & 33,2019 & 304,9052 & 8,5022 & 3,3803 & 8,6188 \\
\hline \multirow{4}{*}{$\mathrm{C} 7$} & Ort & 2,5907 & 15,9209 & 7,3008 & 7,2345 & 15,3555 & 550,4259 & 1,3610 & $1,17 E+07$ & 12,8439 & 31,3497 & 266,9841 & 8,4333 & 1,8315 & 3,8330 \\
\hline & Std & 0,0324 & 0,1522 & 0,5892 & 0,6562 & 1,4450 & 7,6938 & 0,0305 & $9,19 E+05$ & 0,0503 & 1,6194 & 24,1792 & 0,0532 & 0,8903 & 2,4135 \\
\hline & En iyi & 2,5176 & 15,6095 & 6,0394 & 5,3518 & 14,6193 & 514,1951 & 1,2417 & $1,01 E+07$ & 12,7190 & 28,7615 & 198,4121 & 8,3519 & 0,0290 & 1,1628 \\
\hline & En kötü & 2,6236 & 16,1174 & 7,9742 & 7,9970 & 20,6715 & 553,4932 & 1,3872 & $1,28 \mathrm{E}+07$ & 12,8955 & 34,0922 & 304,8869 & 8,5018 & 3,3947 & 8,2303 \\
\hline \multirow{4}{*}{$\mathrm{C} 8$} & Ort & 2,5973 & 15,8259 & 7,2492 & 7,3733 & 15,2402 & 577,7227 & 1,3664 & $1,18 \mathrm{E}+07$ & 12,8240 & 30,9900 & 275,3640 & 8,4233 & 1,9403 & 3,7281 \\
\hline & Std & 0,0412 & 0,5306 & 0,6654 & 0,6111 & 0,7989 & 146,4796 & 0,0226 & $9,10 E+05$ & 0,1344 & 1,4758 & 13,3159 & 0,0711 & 0,8464 & 2,4706 \\
\hline & En iyi & 2,4076 & 13,3190 & 4,8980 & 5,3468 & 14,0735 & 514,5240 & 1,2963 & $1,02 \mathrm{E}+07$ & 12,3405 & 28,5439 & 251,7248 & 8,2673 & 0,0276 & 1,1569 \\
\hline & En kötü & 2,6233 & 16,1161 & 7,9937 & 7,9680 & 17,3395 & 1352,3020 & 1,3877 & $1,28 \mathrm{E}+07$ & 12,8999 & 33,3731 & 296,9698 & 8,5017 & 3,6277 & 9,7045 \\
\hline \multirow{4}{*}{ C9 } & Ort & 2,5907 & 15,9238 & 7,1275 & 7,2222 & 15,4863 & 549,8561 & 1,3718 & $1,21 \mathrm{E}+07$ & 12,8355 & 30,7425 & 273,7712 & 8,3936 & 1,8580 & 2,6943 \\
\hline & Std & 0,0397 & 0,1832 & 1,0437 & 0,6742 & 1,3288 & 7,3661 & 0,0159 & $8,19 E+05$ & 0,0947 & 1,4733 & 18,8937 & 0,0568 & 0,7481 & 1,5974 \\
\hline & En iyi & 2,4492 & 15,3768 & 2,2704 & 5,8911 & 14,4867 & 519,8859 & 1,3181 & $1,03 E+07$ & 12,4495 & 28,1407 & 231,9013 & 8,2583 & 0,0448 & 1,1675 \\
\hline & En kötü & 2,6236 & 16,1200 & 7,8399 & 7,9981 & 19,1155 & 553,5394 & 1,3866 & $1,28 \mathrm{E}+07$ & 12,8977 & 33,5751 & 308,2509 & 8,5006 & 2,8909 & 5,7718 \\
\hline \multirow{4}{*}{$\mathrm{C} 10$} & Ort & 2,5896 & 15,8535 & 7,0448 & 7,0796 & 15,1402 & 591,4097 & 1,3750 & $1,19 E+07$ & 12,8267 & 31,5494 & 273,2578 & 8,4016 & 1,9810 & 3,2256 \\
\hline & Std & 0,0371 & 0,2242 & 0,7921 & 0,6919 & 0,8425 & 156,3896 & 0,0144 & $8,85 E+05$ & 0,0868 & 1,3433 & 20,9193 & 0,0595 & 0,8776 & 1,9997 \\
\hline & En iyi & 2,5003 & 15,3484 & 5,1097 & 4,8766 & 14,3109 & 540,9990 & 1,3392 & $1,02 \mathrm{E}+07$ & 12,5066 & 29,2098 & 223,0550 & 8,2349 & 0,0327 & 1,1531 \\
\hline & En kötü & 2,6284 & 16,1237 & 7,9699 & 7,9198 & 18,8727 & 1259,9595 & 1,3897 & $1,28 \mathrm{E}+07$ & 12,8953 & 33,6620 & 309,3080 & 8,5014 & 3,3343 & 7,1752 \\
\hline
\end{tabular}


Tablo 7’ de S ölçütüne göre istatistiksel verilerde ortalama değeri göz önüne alındığında, F4,F6,F7 ve F14 fonksiyonlarında C6, F5,F10 ve F12' de C7, F2 ve F9 fonksiyonlarında C5 ve F11 ve F13 fonksiyonlarında MOGoldSA başarılı sonuçlar ortaya koymuştur. Bunun yanı sıra C4 F1 fonksiyonunda ve C10 ise F8 fonksiyonunda başarılı sonuçlar üreten kaotik haritalı optimizasyon algoritması olmuştur.

Tablo 7: S ölçütüne göre istatistiksel sonuçlar (İ: istatistiksel, Ort: ortalama değer, M: MOGoldSA, C1C10: Kaotik haritalı MOGoldSA)

\begin{tabular}{|c|c|c|c|c|c|c|c|c|c|c|c|c|c|c|c|}
\hline$F$ & $\dot{I}$ & F1 & $\mathrm{F} 2$ & F3 & $\mathrm{F} 4$ & F5 & F6 & F7 & F8 & F9 & F10 & F11 & F12 & F13 & F14 \\
\hline \multirow{2}{*}{$\mathrm{N}$} & Ort & 7130 & 3,7271 & ,3854 & 1,2068 & 6215 & 121,9921 & 0,0947 & $62 E+06$ & 8061 & 4,3212 & 3,2750 & 1,9543 & 1209 & 0,3769 \\
\hline & En iyi & 4882 & 9373 & 8477 & 5627 & 7529 & ,3183 & 0603 & $74 \mathrm{E}+06$ & 0014 & 2676 & 8832 & 2822 & 0056 & 0711 \\
\hline \multirow{3}{*}{$\mathrm{C}$} & Ort & 301 & 468 & 3995 & 2400 & 509 & & 5565 & $4 E+06$ & 3093 & 2667 & 0644 & 6991 & 3255 & 4437 \\
\hline & Std & 0816 & ,6125 & 4094 & 4431 & 6379 & 0,1504 &, 0112 & $52 E+05$ & 5350 & , 8885 & 7264 &, 4829 & 2790 & , 3257 \\
\hline & En iyi & & 2644 & 7136 & ,3676 & & & & $37 E+06$ & & 2,7209 & & ,7734 & 0103 & ,0310 \\
\hline & Ort & & 5598 & 3166 & 2853 & 5084 & & & $2 E+06$ & & 4123 & & 8176 & &, 3611 \\
\hline & $S t d$ & 707 & 5839 & 4375 & 4490 & 5472 & 64 & 0134 & $7 E+05$ & 4603 & 0,9566 & 344 & 0,2620 & 3122 & ,3609 \\
\hline & En iyi & 1650 & 2434 & 0,5972 & ,4656 & 6542 & 58,8141 & 0278 & $66 E+06$ & 0452 & 2,8516 & 9779 & ,2962 & 0438 &, 0301 \\
\hline & En kötü & 7177 & 4367 & 2,5374 & 2,2695 & 6486 & 160,6832 & 0775 & $74 E+06$ & 7977 & 6,4823 & 0403 & 2,4167 & 0582 &, 4744 \\
\hline \multirow{2}{*}{ C3 } & Ort & & & 4073 & & & & & $9 E+06$ & 8073 & 4,2403 & & & & 4854 \\
\hline & $S t d$ & & 0,5072 & 0,4906 & & & 26, & & $06 E+05$ & 4980 & 0,8396 & & 3288 & 3275 & , 3571 \\
\hline \multirow{3}{*}{ C4 } & & & & & & & & & & & & & & & \\
\hline & En iyi & 4013 & 2,7758 & 0,3400 & 0,6281 & 4750 & 27,46 & & $E+06$ & 70 & 3,0348 & & & &, 0406 \\
\hline & En köt & & & & & & & & & & & & & & \\
\hline \multirow{4}{*}{$\mathrm{C} 5$} & Ort & & 892 & 1612 & & & & & $E+06$ & & & & & & 223 \\
\hline & $S t d$ & & & 3640 & & & & & $E+05$ & & & & & & \\
\hline & En iyi & 4374 & 1,8822 & 0,6046 & 0,4706 & 5163 & 59,8 & & $4 E+06$ & & & & & & 0,0339 \\
\hline & En kötü & 7803 & 3849 & 2,2641 & 2,0438 & 3,8524 & 380 , & 0,0850 & $3 E+06$ & 2,7060 & 5,6040 & 4118 & 2,3567 & 1596 & 1,0479 \\
\hline \multirow{4}{*}{ C6 } & Ort & & & & & & & & $4 E+06$ & & & & & & \\
\hline & $S t d$ & & & 4659 & & & & & $E+05$ & & & & & & 2906 \\
\hline & En iyi & & & 0,4391 & & & & & $E+06$ & & & & & & \\
\hline & En kötü & 3016 & & 2,6339 & & & & & $3 E+06$ & 2,8209 & 6,2561 & & & & 0143 \\
\hline \multirow{4}{*}{ C9 } & Ort & 5952 & & 1,2355 & & & & & & & & & & & \\
\hline & Std & 0990 & 0,4861 & 0,4865 & 0,4716 & 0,4224 & 19,8393 & & $3,62 E+05$ & 0,3358 & 0,9329 & 2831 & 0,3195 & 2564 & 0,3264 \\
\hline & En iyi & & 2,2201 & 0,1912 & & & 68,5404 & & $1,93 E+06$ & & & & & & 0,0461 \\
\hline & En kötü & 0,7742 & 4,2890 & 2,5498 & 2,1881 & & 147,2186 & 0,0802 & $3,48 \mathrm{E}+06$ & 2,5629 & 6,3252 & & 2,2829 & 8099 & 1,1283 \\
\hline \multirow{4}{*}{$\mathrm{C} 10$} & Ort & 6149 & 3,5178 & 1,2517 & & & & 0,0524 & $2,47 E+06$ & 1,9336 & 4,6251 & & 1,7240 & 3165 & 0,3454 \\
\hline & Std & & & 0,4667 & & & & & $4,90 E+05$ & & & & & & 0,2827 \\
\hline & En iyi & & 2,2609 & 0,3062 & 0,3648 & 1,3449 & 65,6300 & 0,0277 & $1,53 E+06$ & 0,7348 & 2,6110 & 1,5699 & 0,9884 & 0,0053 & 0,0359 \\
\hline & En kötü & 0,8038 & 4,8998 & 2,1961 & 2,8677 & 3,7212 & 297,2367 & 0,0823 & $3,23 E+06$ & 2,9062 & 6,6507 & 16,6164 & 2,3321 & 1,3040 & 0,9333 \\
\hline
\end{tabular}

Tablo 8' de SP ölçütüne göre istatistiksel verilerde ortalama değeri göz önüne alındığında, MOGoldSA F1, F6, F7, F9 ve F11-F14 kıyaslama fonksiyonlarında en iyi sonucu üreten algoritma olmuştur. MOGoldSA' yı F4 ve F10 fonksiyonlarında başarılı sonuçlar üreten $\mathrm{C} 3$ takip etmektedir. $\mathrm{C} 4, \mathrm{C} 5$ ve $\mathrm{C} 6$ kaotik haritalı optimizasyon algoritmaları ise sırasıyla F8, F2 ve F3 fonksiyonlarında başarılı sonuçlar üretmiştir. 
Tablo 8: SP ölçütüne göre istatistiksel sonuçlar (İ: istatistiksel, Ort: ortalama değer, M: MOGoldSA, C1C10: Kaotik haritalı MOGoldSA)

\begin{tabular}{|c|c|c|c|c|c|c|c|c|c|c|c|c|c|c|c|}
\hline$F$ & $\dot{I}$ & F1 & F2 & F3 & F4 & F5 & F6 & F7 & F8 & F9 & F10 & F11 & F12 & F13 & F14 \\
\hline \multirow{4}{*}{ M } & Ort & 0,8793 & 0,8870 & 1,2469 & 1,3256 & 0,9176 & 0,9380 & 0,7270 & 0,8146 & 0,9175 & 1,1735 & 0,7392 & 0,9355 & 0,8864 & 1,0225 \\
\hline & Std & 0,0640 & 0,0190 & 0,1658 & 0,2013 & 0,1167 & 0,0439 & 0,0488 & 0,0486 & 0,0261 & 0,0468 & 0,0722 & 0,1044 & 0,1260 & 0,2028 \\
\hline & En iyi & 0,7628 & 0,8402 & 0,8927 & 0,7715 & 0,7183 & 0,8505 & 0,6420 & 0,7322 & 0,8794 & 1,0623 & 0,5707 & 0,7396 & 0,6177 & 0,8036 \\
\hline & En kötü & 1,0124 & 0,9243 & 1,5324 & 1,5851 & 1,1403 & 1,0225 & 0,8420 & 0,9246 & 0,9886 & 1,2750 & 0,8726 & 1,1161 & 1,0866 & 1,3920 \\
\hline \multirow{4}{*}{$\mathrm{C} 1$} & Ort & 0,9488 & 0,8882 & 1,3063 & 1,2726 & 0,8835 & 1,0200 & 0,8993 & 0,8313 & 0,9210 & 1,1743 & 0,7795 & 1,0202 & 0,9059 & 1,0690 \\
\hline & Std & 0,0583 & 0,0238 & 0,1768 & 0,2049 & 0,0909 & 0,0577 & 0,0945 & 0,0491 & 0,0247 & 0,0532 & 0,0732 & 0,1078 & 0,0610 & 0,1804 \\
\hline & En iyi & 0,8329 & 0,8388 & 0,8309 & 0,8060 & 0,7221 & 0,9225 & 0,7316 & 0,7538 & 0,8749 & 1,0478 & 0,6467 & 0,8140 & 0,7888 & 0,8436 \\
\hline & En kötü & 1,0770 & 0,9372 & 1,5839 & 1,6278 & 1,0937 & 1,1226 & 1,1348 & 0,9559 & 0,9726 & 1,2880 & 0,9361 & 1,2143 & 1,0498 & 1,4409 \\
\hline \multirow{4}{*}{$\mathrm{C} 2$} & Ort & 0,9611 & 0,8929 & 1,3187 & 1,2699 & 0,9080 & 1,0104 & 0,9251 & 0,8152 & 0,9217 & 1,1760 & 0,7677 & 1,0162 & 0,9088 & 1,0632 \\
\hline & Std & 0,0565 & 0,0283 & 0,1739 & 0,2472 & 0,0949 & 0,0641 & 0,0847 & 0,0503 & 0,0275 & 0,0480 & 0,0721 & 0,0847 & 0,0477 & 0,1554 \\
\hline & En iyi & 0,8695 & 0,8335 & 0,8478 & 0,6326 & 0,7723 & 0,8890 & 0,7955 & 0,6911 & 0,8558 & 1,0502 & 0,6715 & 0,8880 & 0,8434 & 0,8260 \\
\hline & En kötü & 1,0841 & 0,9501 & 1,5656 & 1,6520 & 1,0717 & 1,2096 & 1,1566 & 0,8988 & 0,9701 & 1,2763 & 0,9168 & 1,1725 & 1,0604 & 1,3411 \\
\hline \multirow{4}{*}{ C3 } & Ort & 0,9881 & 0,8977 & 1,2835 & 1,2379 & 0,8987 & 1,0252 & 0,9413 & 0,8259 & 0,9268 & 1,1647 & 0,7785 & 1,0156 & 0,9235 & 1,1560 \\
\hline & Std & 0,0789 & 0,0273 & 0,2082 & 0,1875 & 0,0907 & 0,0607 & 0,0830 & 0,0604 & 0,0202 & 0,0447 & 0,0687 & 0,0827 & 0,0660 & 0,1876 \\
\hline & En iyi & 0,8185 & 0,8494 & 0,8452 & 0,9018 & 0,7413 & 0,9200 & 0,7786 & 0,7362 & 0,8912 & 1,0676 & 0,5807 & 0,8384 & 0,8201 & 0,8573 \\
\hline & En kötü & 1,1254 & 0,9765 & 1,5818 & 1,6266 & 1,0921 & 1,1607 & 1,0853 & 0,9613 & 0,9703 & 1,2365 & 0,9221 & 1,1934 & 1,1351 & 1,4104 \\
\hline \multirow{4}{*}{$\mathrm{C} 4$} & Ort & 0,9840 & 0,8891 & 1,3378 & 1,2364 & 0,9360 & 1,0105 & 0,9222 & 0,8031 & 0,9277 & 1,1758 & 0,7538 & 1,0299 & 0,9324 & 1,1022 \\
\hline & Std & 0,0713 & 0,0278 & 0,1671 & 0,2020 & 0,0864 & 0,0624 & 0,0968 & 0,0703 & 0,0257 & 0,0477 & 0,0709 & 0,0888 & 0,0625 & 0,1698 \\
\hline & En iyi & 0,8601 & 0,8487 & 0,9594 & 0,8050 & 0,7964 & 0,9010 & 0,7590 & 0,6571 & 0,8841 & 1,0758 & 0,5816 & 0,8191 & 0,8042 & 0,8662 \\
\hline & En kötü & 1,1948 & 0,9653 & 1,5601 & 1,5915 & 1,1299 & 1,1539 & 1,1234 & 0,9585 & 0,9856 & 1,2469 & 0,8555 & 1,1661 & 1,0723 & 1,4048 \\
\hline \multirow{4}{*}{ C5 } & Ort & 0,9716 & 0,8853 & 1,2788 & 1,2805 & 0,9155 & 1,0210 & 0,8794 & 0,8178 & 0,9282 & 1,1880 & 0,7865 & 1,0089 & 0,9162 & 1,0754 \\
\hline & Std & 0,0703 & 0,0226 & 0,2487 & 0,2512 & 0,0994 & 0,0731 & 0,1116 & 0,0548 & 0,0265 & 0,0374 & 0,0806 & 0,1028 & 0,0487 & 0,1749 \\
\hline & En iyi & 0,8353 & 0,8416 & 0,8252 & 0,6652 & 0,7413 & 0,8857 & 0,6672 & 0,7311 & 0,8744 & 1,1227 & 0,6374 & 0,7770 & 0,8331 & 0,8718 \\
\hline & En kötü & 1,1128 & 0,9285 & 1,5890 & 1,6746 & 1,1581 & 1,2143 & 1,1103 & 0,9646 & 0,9837 & 1,2739 & 0,9414 & 1,1837 & 1,0026 & 1,3892 \\
\hline \multirow{4}{*}{ C6 } & Ort & 0,9459 & 0,8907 & 1,2419 & 1,2513 & 0,9203 & 1,0121 & 0,9364 & 0,8157 & 0,9193 & 1,1859 & 0,7728 & 1,0197 & 0,9187 & 1,1358 \\
\hline & Std & 0,0706 & 0,0274 & 0,2337 & 0,2117 & 0,1038 & 0,0476 & 0,1126 & 0,0495 & 0,0222 & 0,0416 & 0,0753 & 0,0756 & 0,0644 & 0,1799 \\
\hline & En iyi & 0,7745 & 0,8325 & 0,7609 & 0,8450 & 0,7587 & 0,9229 & 0,6672 & 0,6928 & 0,8799 & 1,1015 & 0,6204 & 0,8807 & 0,8153 & 0,8787 \\
\hline & En kötü & 1,0737 & 0,9534 & 1,5658 & 1,6052 & 1,1851 & 1,1169 & 1,1731 & 0,8808 & 0,9634 & 1,2570 & 0,9520 & 1,1696 & 1,0904 & 1,4116 \\
\hline \multirow{4}{*}{$\mathrm{C} 7$} & Ort & 0,9850 & 0,9028 & 1,3567 & 1,2843 & 0,8838 & 1,0214 & 0,8963 & 0,8312 & 0,9206 & 1,1820 & 0,7914 & 1,0152 & 0,9215 & 1,0975 \\
\hline & Std & 0,0662 & 0,0252 & 0,1804 & 0,2558 & 0,0933 & 0,0614 & 0,0798 & 0,0799 & 0,0262 & 0,0458 & 0,0863 & 0,0812 & 0,0626 & 0,1983 \\
\hline & En iyi & 0,8555 & 0,8699 & 0,9144 & 0,6039 & 0,6264 & 0,9211 & 0,7806 & 0,6651 & 0,8764 & 1,1057 & 0,6740 & 0,7928 & 0,7854 & 0,8627 \\
\hline & En kötü & 1,1445 & 0,9738 & 1,5911 & 1,6429 & 1,0715 & 1,1686 & 1,0450 & 0,9865 & 0,9932 & 1,2757 & 0,9767 & 1,1484 & 1,0457 & 1,4384 \\
\hline \multirow{4}{*}{$\mathrm{C} 8$} & Ort & 0,9564 & 0,8908 & 1,2946 & 1,2804 & 0,8890 & 1,0113 & 0,9125 & 0,8080 & 0,9254 & 1,1760 & 0,7866 & 1,0099 & 0,9004 & 1,1656 \\
\hline & Std & 0,0627 & 0,0325 & 0,1807 & 0,2256 & 0,1003 & 0,0810 & 0,0915 & 0,0638 & 0,0251 & 0,0615 & 0,0750 & 0,1010 & 0,0666 & 0,1795 \\
\hline & En iyi & 0,7929 & 0,8537 & 0,9247 & 0,5886 & 0,6958 & 0,8954 & 0,7440 & 0,6951 & 0,8649 & 1,0586 & 0,6552 & 0,8361 & 0,8010 & 0,8582 \\
\hline & En kötü & 1,0588 & 0,9822 & 1,5012 & 1,5997 & 1,1547 & 1,3793 & 1,1016 & 0,9358 & 0,9873 & 1,2993 & 0,9163 & 1,2135 & 1,1227 & 1,4428 \\
\hline \multirow{4}{*}{ C9 } & Ort & 0,9628 & 0,8859 & 1,3441 & 1,2834 & 0,8998 & 1,0045 & 0,9081 & 0,8060 & 0,9274 & 1,1781 & 0,7721 & 1,0032 & 0,9049 & 1,0237 \\
\hline & Std & 0,0709 & 0,0199 & 0,2085 & 0,2577 & 0,0956 & 0,0566 & 0,1000 & 0,0681 & 0,0322 & 0,0561 & 0,0825 & 0,0854 & 0,0684 & 0,1531 \\
\hline & En iyi & 0,8028 & 0,8541 & 0,8961 & 0,6132 & 0,7131 & 0,8988 & 0,7362 & 0,6844 & 0,8753 & 1,0417 & 0,6031 & 0,8201 & 0,7368 & 0,8435 \\
\hline & En kötü & 1,0746 & 0,9471 & 1,5932 & 1,6154 & 1,1361 & 1,1358 & 1,1556 & 0,9166 & 1,0109 & 1,2819 & 0,9425 & 1,1805 & 1,0166 & 1,4465 \\
\hline \multirow{4}{*}{$\mathrm{C} 10$} & Ort & 0,9615 & 0,8914 & 1,2862 & 1,2837 & 0,9169 & 1,0322 & 0,8893 & 0,8128 & 0,9335 & 1,1824 & 0,8188 & 1,0119 & 0,9116 & 1,0799 \\
\hline & Std & 0,0772 & 0,0312 & 0,2042 & 0,2228 & 0,1192 & 0,1072 & 0,0767 & 0,0621 & 0,0327 & 0,0371 & 0,0824 & 0,0811 & 0,0635 & 0,1716 \\
\hline & En iyi & 0,8087 & 0,8151 & 0,7356 & 0,8445 & 0,7505 & 0,9240 & 0,7496 & 0,6983 & 0,8891 & 1,0962 & 0,6285 & 0,8841 & 0,7674 & 0,8464 \\
\hline & En kötü & 1,0693 & 0,9490 & 1,5566 & 1,5358 & 1,2755 & 1,4355 & 1,0847 & 0,9752 & 0,9924 & 1,2448 & 0,9520 & 1,1847 & 1,0908 & 1,3578 \\
\hline
\end{tabular}

\section{Sonuçlar}

Çok amaçlı altın sinüs algoritmasının (MOGoldSA) performansını iyileştirmek için kaotik haritalar kullanılmıştır. Kaotik haritalar MOGoldSA' nın geniş arama alanına ulaşmasına ve sömürü evresine yavaş yavaş geçmesine yardımcı olmaktadır. Bu performans verilerinden yola çıkılarak çok amaçlı optimizasyonda başlangıçta kullanılan rasgele sayı dizelerine yapılan küçük müdahaleler sonucunda, probleme uygun çözümler üretmede daha iyi sonuçlar alındığı görülmüştür. Çalışmada kullanılan kısıtlı, kısıtsız ve mühendislik problemlerine uygun çözümler üretmede kaotik haritalar genel olarak başarılı sonuçlar üretmiştir. GD ve RGD ölçütünde Chebyshev ve Singer, MS ve S ölçütünde Parçalı ve Sinüs, SP ölçütüne göre de Gauss/Mouse kaotik haritaları başarılı sonuçlar ortaya koymuştur. Bu başarılar sonucunda, kaotik haritalar ile birleştirilmiş MOGoldSA' nın iyileştirme yeteneğine sahip olduğu kanttlanmıştır. Gelecek çalışmalarda gerçek yaşam problemleri üzerinde uygulanarak daha verimli kaotik temelli çok amaçlı optimizasyon algoritması oluşturma hedeflenmektedir. 


\section{Kaynaklar}

[1] Mirjalili S, Lewis A. The Whale Optimization Algorithm. Adv Eng Softw, 2016; 95: 51-67

[2] Tanyıldızı E, Cigal T. Kaotik Haritalı Balina Optimizasyon Algoritmaları. Fırat Üniversitesi Müh Bil Dergisi, 2017; 29(1): $307-317$.

[3] Tanyıldızı E, Demir G. Nümerik Optimizasyon için Kaotik Altın Sinüs Algoritması. Fırat Üniversitesi Müh Bil Dergisi, 2019; 31(1): $91-97$.

[4] Danqing G, Junping W, Jun H. Renmin H and Maoqiang S. Chaotic-NSGA-II: An effective algorithm to solve multiobjective optimization problems. ICISS 2010; Guilin, China.

[5] Ying S, Yuelin G,Xudong S. Chaotic Multi-Objective Particle Swarm Optimization Algorithm Incorporating Clone Immunity. Mathematics, 2019; 7(146):1-16.

[6] Dunia S. Ramzy A. A Chaotic Crow Search Algorithm for High-Dimensional Optimization Problems. Basrah Journal for Engineering Sciences January 2018; 17(1):15-25

[7] Wei G. Shoubin W. Chaos Ant Colony Optimization and Application. Fourth International Conference on Internet Computing for Science and Engineering, 2009; Harbin, China.

[8] Zhang H. Zhou J. Zhang Y. Fang N. and Zhang R. Short term hydrothermal scheduling using multi-objective differential evolution with three chaotic sequences. Int J Elec Power, 2013; 47: 85-99.

[9] Ayan K. and Kilic U. Solution of multi-objective optimal power flow with chaotic artificial bee colony algorithm. Int Rev Electr Eng-I; 2011; 6(3):1365-1371.

[10] Pei Y. and Hao J, "Non-dominated sorting and crowding distance based multi-objective chaotic evolution", ICSI 2017; Japan, pp. 15-22,

[11] Tanyıldızı E, Demir G. Golden Sine Algorithm: A Novel Math-Inspired Algorithm. Adv Electr Comput En, 2017; 17(2):71-78.

[12] Eröz E. Yeni Çok Amaçlı Optimizasyon Algoritması: MOGoldSA, Fırat Üniversitesi Teknoloji Fakültesi Yazılım Mühendisliği Yüksek Lisans Tezi, 2020

[13] Mirjalili S, Gandomi AH. Chaotic gravitational constants for the gravitational search algorithm. Appl Soft Comput, 2017. 53: 407-419.

[14] Deb K. Multi-objective optimization using evolutionary algorithms. New York: John Wiley\&Sons, 2001.

[15] Van Veldhuizen, DA and Lamont GB. Multiobjective evolutionary algorithm research: A history and analysis. Technical Report TR-98-03, Department of Electrical and Computer Engineering, Graduate School of Engineering, Air Force Institute of Technology, WrightPatterson AFB, Ohio, 1998

[16] Zitzler E. Evolutionary Algorithms for Multiobjective Optimization: Methods and Applications, Ph.D Thesis, Swiss Federal Institute of Technology, Switzerland. 1999.

[17] Miettinen K. Nonlinear multiobjective optimization, Kluwer Academic Publishers, Boston: SpringerScience\& Bus Media. 1999.

[18] Schott JR. Fault Tolerant Design Using Single and Multi-Criteria Genetic Algorithms. Master of Science Thesis, Massachusetts Institute of Technology, Cambridge, 1995. 